\section{ECOHFTOR}

Make Your Publications Visible.
A Service of

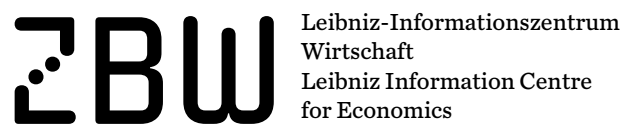

Gobillon, Laurent; Milcent, Carine

\title{
Working Paper \\ Competition and Hospital Quality: Evidence from a French Natural Experiment
}

IZA Discussion Papers, No. 10476

Provided in Cooperation with:

IZA - Institute of Labor Economics

Suggested Citation: Gobillon, Laurent; Milcent, Carine (2017) : Competition and Hospital Quality: Evidence from a French Natural Experiment, IZA Discussion Papers, No. 10476, Institute of Labor Economics (IZA), Bonn

This Version is available at:

http://hdl.handle.net/10419/161099

\section{Standard-Nutzungsbedingungen:}

Die Dokumente auf EconStor dürfen zu eigenen wissenschaftlichen Zwecken und zum Privatgebrauch gespeichert und kopiert werden.

Sie dürfen die Dokumente nicht für öffentliche oder kommerzielle Zwecke vervielfältigen, öffentlich ausstellen, öffentlich zugänglich machen, vertreiben oder anderweitig nutzen.

Sofern die Verfasser die Dokumente unter Open-Content-Lizenzen (insbesondere CC-Lizenzen) zur Verfügung gestellt haben sollten, gelten abweichend von diesen Nutzungsbedingungen die in der dort genannten Lizenz gewährten Nutzungsrechte.
Terms of use:

Documents in EconStor may be saved and copied for your personal and scholarly purposes.

You are not to copy documents for public or commercial purposes, to exhibit the documents publicly, to make them publicly available on the internet, or to distribute or otherwise use the documents in public.

If the documents have been made available under an Open Content Licence (especially Creative Commons Licences), you may exercise further usage rights as specified in the indicated licence. 


\section{Z A Institute of Labor Economics}

Initiated by Deutsche Post Foundation

\section{DISCUSSION PAPER SERIES}

IZA DP No. 10476

Competition and Hospital Quality: Evidence from a French Natural Experiment

Laurent Gobillon

Carine Milcent 


\title{
I Z A Institute of Labor Economics
}

Initiated by Deutsche Post Foundation

\section{DISCUSSION PAPER SERIES}

IZA DP No. 10476

\section{Competition and Hospital Quality: Evidence from a French Natural Experiment}

\author{
Laurent Gobillon \\ Paris School of Economics - CNRS, \\ CEPR and IZA
}

\section{Carine Milcent}

Paris School of Economics - CNRS

Any opinions expressed in this paper are those of the author(s) and not those of IZA. Research published in this series may include views on policy, but IZA takes no institutional policy positions. The IZA research network is committed to the IZA Guiding Principles of Research Integrity.

The IZA Institute of Labor Economics is an independent economic research institute that conducts research in labor economics and offers evidence-based policy advice on labor market issues. Supported by the Deutsche Post Foundation, IZA runs the world's largest network of economists, whose research aims to provide answers to the global labor market challenges of our time. Our key objective is to build bridges between academic research, policymakers and society.

IZA Discussion Papers often represent preliminary work and are circulated to encourage discussion. Citation of such a paper should account for its provisional character. A revised version may be available directly from the author. 


\section{ABSTRACT}

\section{Competition and Hospital Quality: Evidence from a French Natural Experiment ${ }^{*}$}

We evaluate the effect of a pro-competition reform gradually introduced in France over the 2004-2008 period on hospital quality measured with the mortality of heart-attack patients. Our analysis distinguishes between hospitals depending on their status: public (university or non-teaching), non-profit or for-profit. These hospitals differ in their degree of managerial and financial autonomy as well as their reimbursement systems and incentives for competition before the reform, but they are all under a DRG-based payment system after the reform. For each hospital status, we assess the benefits of local competition in terms of decrease in mortality after the reform. We estimate a duration model for mortality stratified at the hospital level to take into account hospital unobserved heterogeneity and censorship in the duration of stays in a flexible way. Estimations are conducted using an exhaustive dataset at the patient level over the 1999-2011 period. We find that non-profit hospitals, which have managerial autonomy and no incentive for competition before the reform, enjoyed larger declines in mortality in places where there is greater competition than in less competitive markets.

JEL Classification:

111,118

Keywords:

competition, hospital ownership, policy evaluation, heart attack

\section{Corresponding author:}

Laurent Gobillon

PSE-CNRS

48 Boulevard Jourdan

75014 Paris

France

E-mail: laurent.gobillon@psemail.eu

\footnotetext{
* We are grateful to Jon Magnussen, Luigi Siciliani, Jonathan Skinner, Peter Smith as well as the participants to the CEPREMAP conference in Paris "Hospital: competition and reimbursement" for useful comments and discussion. We also thank the members of the Agence Technique d'Information sur I'Hospitalisation (ATIH) for their helpful assistance.
} 


\section{Introduction}

Whereas the healthcare system has long been market-oriented in the US, it was traditionally strongly regulated and more centralized in European countries. However, these countries face the major challenge of keeping health expenditures under control while increasing the efficiency of their healthcare system. It is widely considered that such a goal can be achieved by giving a greater role to market forces. As a result, a number of countries have implemented healthcare reforms to increase decentralization and favour competition. The Netherlands, Germany, the United Kingdom and France are some good examples. In the Netherlands, there were attempts to increase the merger activity after the market liberalization (Canoy and Sauter, 2009). In Germany, the most notable change was the acquisition of public hospitals by private hospital systems. In the UK, reforms were initiated to promote competition among hospitals which were exclusively state-owned (Cooper et al., 2011).

In this paper, we evaluate the effect on hospital quality of the pro-competition reform which was gradually introduced in France over the 2004-2008 period. The reform induced competition by imposing a Diagnostic Related Group (DRG) based payment system to both the public and private sectors. As prices are set administratively in France, competition can only occur in quality.

A specificity of the French healthcare system is that both sectors provide care of high quality and they both treat a significant share of patients. Before the reform, reimbursement rules differed between the two sectors. The private sector consists of for-profit hospitals which were paid fees for services. These hospitals already competed with each other for patients attracted to the private sector by the good quality of catering and accommodation services. The reform did not alter the competition process but may have intensified competition. As prices were not affected, it is likely that patients' propensity to choose the private sector did not change and forprofit hospitals kept the same healthcare demand. Overall, it is expected that the pro-competition reform did not affect for-profit hospitals in a sizable way.

By contrast, hospitals in the public sector were subject to a global budget system before the reform. They include non-profit hospitals which have a high degree of managerial autonomy and state-owned hospitals which have none. Among state-owned hospitals, university establishments receive substantial additional funding for $R \& D$ and teaching activities. Besides, their reputation as high-tech hospitals makes them benefit from a captive demand. As a result, the financial incentives to attract patients to increase the budget are weak and university hospitals 
are not expected to be significantly affected by the reform. Overall, it is only non-profit and nonteaching state-owned hospitals that are under financial pressure with the reform, and the difference in their reaction should capture the effect of managerial autonomy.

There is a recent and growing empirical literature on the relationship between competition and hospital quality on fixed-price markets which focuses mostly on the US and the UK (for an extensive survey, see Gaynor and Town, 2013). Competition is usually measured with a Herfindhal-Hirschmann index (HHI) which is defined as the sum of squares of all hospital market shares within a given area. Quality of services is commonly approximated with mortality which is not a measure of quality per se, but rather an outcome partially determined by quality. The main reason is that mortality varies with the severity of illness and there is some heterogeneity in this severity across patients. It is therefore important to properly take into account the case-mix of patients in the analysis. Patients admitted in hospitals for an Acute Myocardial Infarction (AMI) or heart attack are studied extensively in the literature as the mortality rate for heart attack is considered to be a good indicator of the overall hospital quality. ${ }^{1}$

Studies on the US focus on Medicare patients for whom prices are fixed and exploit spatial variations in the local concentration of hospitals. Results are rather mixed: whereas Kessler and McClellan (2000) and Kessler and Geppert (2005) find that local competition lowers mortality of heat-attack patients, Mukamel et al. (2001) find no effect. According to Gowrisakaran and Town (2003), local competition increases mortality in California. The effect of competition on mortality would depend on the information that patients are able to recover on hospital quality (Chou et al., 2014) and on the reimbursement rate of patients' insurance (Shen, 2003). If hospitals are underpaid by a given insurance, they have little incentive to compete on quality for patients covered by that insurance. In France, all patients are covered by the same health insurance.

There is also a recent and significant literature on the UK which estimates the effect of competition on quality by exploiting time variations in the intensity of local competition caused by a pro-competition reform introduced over the 2002-2006 period (Cooper et al., 2011; Gaynor et al., 2013). This reform gave more managerial autonomy to hospitals and changed the reimbursement rules to a DRG-based payment system. It also provided patients with more freedom of hospital choice and more information on hospital quality. ${ }^{2}$ It is shown by Cooper et al. (2011) that the reform led to a decrease in mortality trend in more competitive local markets.

\footnotetext{
${ }^{1}$ A recent exception is Bynum et al. (2016) who study the effect of hospital competition not only for heart attack but also for hip and knee replacement, and dementia.

${ }^{2}$ Gaynor et al. (2016) show that the larger freedom of choice for patients increased the demand elasticity faced by hospitals with regards to quality and waiting time for Coronary Artery Bypass Graft (CABG) surgery which is used to treat heart attack patients.
} 
Gaynor et al. (2013) obtain similar results for mortality in level and additionally find that the reform saved lives without raising costs. In fact, most prominent scholars consider that the UK reform had positive effects on hospital quality (Bloom et al., 2011). ${ }^{3}$ One channel through which this would occur is an improvement of management quality (Bloom et al., 2015). Cooper et al. (2016) show that the competition from small private surgical centres which were allowed to enter the market after the UK reform improved the efficiency of public hospitals. This assessment is restricted to the outcomes for a single type of hospitals since there are only public hospitals in the UK before the reform. ${ }^{4}$

In our context, we can distinguish four hospital statuses: for-profit, university, nonteaching public and non-profit. We evaluate the impact of the French pro-competition reform by hospital status from an exhaustive dataset of in-hospital patients over 35 admitted for an AMI during the 1999-2011 period. For each hospital status, we assess the effect of the reform using a difference-in-differences approach which consists in quantifying to what extent mortality of heart-attack patients decreased more in more competitive markets than in less competitive markets after the reform. We then compare our difference-in-differences estimates across hospital statuses to assess the importance of the reimbursement rule and managerial autonomy before the reform. This amounts to making triple differences.

In practice, we estimate a duration model for mortality stratified at the hospital level to take into account hospital unobserved heterogeneity and censorship in the duration of stays in a flexible way. We use the usual HHI as a measure of market structure, as well as the LOgit Concentration Index (LOCI) introduced by Akosa, Gaynor and Vogt (2006), and an HHI that takes into account the potential endogeneity of patients' choice of hospital (Kessler and McClellan, 2001). We find that the reform had a sizable negative competition effect on mortality for non-profit public hospitals. This means that non-profit hospitals located in places where there is greater competition enjoyed larger declines in mortality than those in less competitive markets. This result can be explained by managerial autonomy that allows non-profit hospitals to make adjustments to be competitive. By contrast, we do not find any significant competition effect of the reform for university, non-teaching public and for-profit hospitals. Consistent explanations are that university hospitals do not participate to competition because they treat atrisk patients not profitable for other hospitals and get enough additional funding from the

\footnotetext{
3 One concern could be that hospital competition harms equity among areas, but evidence suggests that this was not the case in the UK (Cookson et al., 2013).

${ }^{4}$ Related to our work, O'Keeffe and Skellern (2015) assess whether altruistic and non-altruistic hospitals responded differently to the introduction of competition in the UK, altruism being measured at the manager level. They find that low-altruism hospitals increased their quality in response to local competition to a larger extent than highaltruism hospitals. In France, we expect altruism to be more important in the public sector, in particular in stateowned hospitals.
} 
government, non-teaching public hospitals are unable to adjust to competition because they do not have any managerial autonomy, and for-profit hospitals were already competing for funding before the pro-competition reform was introduced. Our results are robust to the use of our alternative measures of local competition.

We also propose a counterfactual exercise to recover the probability of death within 5 days if there was no competition effect of the reform. For non-profit hospitals, this counterfactual probability in 2011 is larger by as much as 5.4 points than the observed probability (which is $2.8 \%$ ) with a rather narrow confidence interval of [ $4.46 ; 6.32]$, but non-profit hospitals provide care to only a small share of patients. For the overall sample of patients, the counterfactual probability is larger by only 0.16 points than the observed probability.

The rest of the paper is organized as follows. Section 2 presents the French healthcare system and the pro-competition reform. It also gives some information on our quality indicator and our main measure of local competition. We detail our empirical strategy in Section 4 and comment the results in Section 5. We provide robustness checks in Section 6 and we finally conclude in Section 7.

\section{Context}

\subsection{The French healthcare system and pro-competition reform}

In France, the hospital healthcare system is funded publicly. There are three hospital ownership statuses: state-owned, non-profit and for-profit, which characteristics are summarized in Figure 1.

\section{[ Insert Figure 1]}

We now describe their funding, explain how it was affected by the reform of the hospital healthcare system which took place over the 2004-2008 period, and speculate on the extent to which this reform may have induced competition.

Prior to the reform, hospitals in the public sector (which include both non-profit and state-owned facilities) received a global budget which amount was fixed mainly for historical reasons. They did not have any incentive to attract patients, and they could choose whether or not to work cooperatively, depending on their own will and the influence from local health authorities. In March 2004, the reform called "Tarification à l'activité” — T2A was introduced, and a Diagnostic Related Groups (DRG) based payment system was gradually implemented. The proportion of hospitals under this new reimbursement system was $10 \%$ in $2004,25 \%$ in 2005 , 
$35 \%$ in $2006,50 \%$ in 2007 and $100 \%$ in 2008 . Nowadays, all public hospitals are paid according to their activity measured by DRGs that take into account the type of pathology, the patient's diagnosis and the degree of pathological severity. A fixed payment is associated to each DRG and the total amount of money received by a hospital depends on the volume of patients with each DRG and the associated fee. ${ }^{5}$ As reimbursement depends on the volume of patients, public hospitals now have incentives to compete for patients. As prices are fixed, they can only compete on quality.

The public sector includes different hospital statuses and we anticipate that the effect of the reform should vary according to the status. Amongst state-owned hospitals, we label as "university hospitals" the facilities to which are assigned teaching and research activities by healthcare authorities. They have high-tech equipment which is funded even when it is not profitable because of their teaching activities and the public mission of dealing with the patients with the most severe health diagnoses. Besides, they keep receiving additional funding for teaching activities after the reform and this loosens their DRG-based payment constraint. University hospitals also have physicians who are highly trained and qualified. All these features make them attractive facilities for patients before and after the reform. They are protected from bankrupt by the State because of their important role in the healthcare system. Finally, as stateowned facilities, they have no managerial or financial autonomy, since medical staff and physicians are civil servants. The staff does not derive any benefit from the profit of their hospital and their employment contract has not been modified by the reform. Therefore, we expect the incentives for competition induced by the reform to have had a very limited effect on the mortality rate in university hospitals.

We label as "non-teaching public hospitals" the other state-owned facilities. They have fewer beds and admissions, and are characterized by a lower availability and use of high-tech equipment. Overall, they are not really attractive for patients. Moreover, they have no managerial autonomy before and after the reform, and it is hard for them to adjust their medical staff because most of them are civil servants. Therefore, any deep change to become more competitive after the reform is difficult to implement. Nevertheless, they receive hardly any additional funding for their public mission compared to university hospitals, and their budget is therefore very sensitive to their activity after the reform. The competition effect of the reform on their healthcare quality therefore seems ambiguous.

The public sector also includes non-profit hospitals which are quite unusual compared to those in other countries. Historically, they were related to a religious order or organisation. They

\footnotetext{
${ }_{5}^{5}$ The transition from a global budget system to a DRG-based payment system for hospitals in the public sector shares some features with the reform that was implemented in the UK over the 2002-2006 period.
} 
were private and concentrated in the East of France. During the 80s-90s, the central State put pressure on them to integrate the public sector with the objective to increase the healthcare supply in that sector. There were big incentives for non-profit facilities to do so since it provided them with the opportunity of getting subsidized and accessing the pool of patients oriented by doctors to public hospitals without distinction of the hospital type. Nevertheless, belonging to the public sector also implies that patients cannot be selected and public service missions need to be fulfilled. ${ }^{6}$ Today, non-profit hospitals are nearly all in the public sector and, since the reform, their budget is entirely determined by their activity. Contrary to state-owned facilities, they have managerial autonomy and their staff is under private labour law. They can thus adjust their labour depending on hospital current and expected activity. ${ }^{7}$ The implementation of the reform may thus have triggered a clear-cut and instantaneous response from non-profit hospitals which can make adjustments to be competitive.

Overall, we expect the competition effect of the reform on hospital quality in the public sector to depend on the degree of managerial autonomy.

In the private sector, hospitals are for-profit and are funded for each stay. Prior to the reform, hospitals received a fee-for-service payment, which amount depended on local health authorities and the procedures implemented during the stay. In March 2005, the fee-for-service reimbursement system was replaced by a DRG-based payment system. ${ }^{8}$ Both systems are based on a competitive mechanism, and the main difference is that for-profit hospitals have to face a larger number of competitors after the reform. Indeed, they then do not compete only among themselves, but also with public hospitals and non-profit ones. Ultimately, the competition effect of the reform on the quality of for-profit hospitals depends on the extent to which the market is locally de-concentrated, public hospitals enter competition and hospital quality is observable by patients. In particular, if the pool of patients usually admitted in for-profit hospitals considers that the public sector is not as attractive as the private sector after the reform, the reform is likely to have no effect on for-profit facilities.

We now consider the hospital choice of patients. Individuals can choose rather freely the facility where they receive care, although their tend to be admitted in their region of residence. Over the 1998-2003 period, 93\% of AMI patients were treated in their region of residence

\footnotetext{
${ }^{6}$ In fact, public missions were already included in missions assigned by religious organisations.

${ }^{7}$ Currently, it is the French non-profit hospitals that are the most comparable with the UK public hospitals, not the university and non-teaching public hospitals.

${ }^{8}$ The transition from a fee-for-service system to a DRG-based payment system for private hospitals is similar to the reform that was implemented in the US in the eighties for Medicare patients.
} 
(Gobillon and Milcent, 2013). There is a unique public health insurance system which covers almost all in-patient expenditures of the whole population, whatever the ownership status of the hospital. A large share of the population (around 95\%) also has a complementary private health insurance that covers mainly dental care, optical care, an additional part of medications for outpatients and additional doctor fees for inpatients admitted in for-profit hospitals.

Patients do not have precise information on the quality of healthcare provided by hospitals even after the reform. Indeed, hospital choice depends mostly on reputation, which is determined by information from relatives and social networks. After the reform, some newspapers decided to establish rankings of hospitals by pathology and may have influenced the reputation of hospitals, but the credibility of these rankings can be questioned and they vary across newspapers. A public website managed by a health authority agency provides information on hospitals. ${ }^{9}$ However, this website is not popular, the information it delivers is hard to interpret to get a quick idea of hospital quality and no information is given on hospital mortality. As a consequence, this website is poorly used by the population. ${ }^{10}$ As quality improvements in some hospitals could remain undetected, incentives for hospitals to compete on quality remain limited.

The competition effect of the reform is likely to depend on the extent to which hospitals face local competitors. In this paper, we assess whether hospitals in more de-concentrated local markets have a healthcare quality which increases more after the pro-competition reform than those in less de-concentrated local markets.

\subsection{Quality indicator}

The health economics literature mostly measures hospital quality with the in-hospital mortality of AMI patients when assessing the effect of local competition on hospital quality (Kessler and McClellan, 2000 ; Kessler and Geppert, 2005 ; Gowrisakaran and Town, 2003 ; Bloom et al., 2011 ; Cooper et al., 2011 ; Gaynor et al., 2013).

There are several reasons why mortality of AMI patients has been investigated extensively by studies on the US and the UK. First, the volume of AMI admissions is large enough and deaths frequent enough to obtain reliable statistical results. This is also true for France, where ischemic diseases are a major cause of mortality. Second, infrastructures for treating AMI patients are common to other hospital services, making AMI mortality a good general marker of hospital quality (Gaynor, 2007). Third, AMI patients are often taken to one of the hospitals close to their

\footnotetext{
${ }^{9}$ http://www.scopesante.fr/.

${ }^{10}$ Patients are much better informed about the performances of hospitals in the UK than in France. In the UK, a government-run website gives some details on various aspects of establishment performances including: riskadjusted mortality rates, hospital activity levels, waiting times and infection rates, all of which are reported by procedure.
} 
place of residence, which means that there is less room for selection biases when studying the effects of local factors, such as local competition, on mortality (Gaynor et al., 2013).

For all these reasons, we chose to study the mortality of AMI patients. Whereas the literature is often interested in the in-hospital probability of death within 30 days, we rather model the duration of stay before death. This allows us to take into account the censorship that occurs when patients are transferred to another hospital or service, or sent back home. This is of particular importance since the behaviour of hospitals can change after the pro-competition reform has been introduced. The estimation of duration models is made possible by the use of patients' data whereas many studies have only been able to use data aggregated at the hospital level. However, as a robustness check, estimated coefficients from linear regressions are also presented and discussed.

When studying mortality, there are some composition effects that should be taken into account with patient characteristics at the individual level. These characteristics include not only age and sex, but also secondary diagnoses and comorbidities. As information on secondary diagnoses and comorbidities is not always available, researchers often use available summary indices such as the Charlson index. In our data, the detailed information on secondary diagnoses and comorbidities allows us to control for them in our regression at the patient level. One may still argue that this information is not enough. McClellan and Staiger (1999) show that when the main secondary diagnoses and comorbidities affecting mortality risk are considered, considerably more detailed medical data do not add much to capture heterogeneity among patients. As Cooper et al. (2011) and Gaynor et al. (2013), we will also control for treatment with angioplasty, which is an innovative procedure used for AMI patient healthcare and which consists in inflating a balloon in a vein or artery to crush a blockage that caused the heart attack.

\subsection{Our indicator for local competition}

A major challenge is to measure local competition with a proper index at the relevant geographic level. This issue is still debated in the literature and alternative proposals have been made by researchers. In this context, we will present results for a specific index similar to that of Cooper et al. (2011) and we will conduct robustness checks using alternative indexes which results are reported in Section $\mathrm{V}$.

Our main measure is an index of local competition centred on the hospital and defined as one minus the average of Herfindahl-Hirschman Indices (HHIs) computed for every patient taking into account establishments within a $30 \mathrm{~km}$ radius around her place of residence. More 
precisely, consider a given patient $i$ and denote by $d_{i k}$ the distance between her place of residence and hospital $k$. The Herfindahl index for that patient, denoted $H H I_{i}$, is given by:

$$
H H I_{i}=\sum_{k \mid d_{i k} \leq 30 k m}\left(\frac{N_{k}}{\bar{N}^{i}}\right)^{2}
$$

where $N_{k}$ is the number of AMI patients in hospital $k$ and $\bar{N}^{i}=\sum_{k \mid d_{i k} \leq 30 \mathrm{~km}} N_{k}$ is the total number of AMI patients within $30 \mathrm{~km}$ of the patient's place of residence. Our index measures hospital competition around the patient. The higher the index, the more competition there is for the patient. When all patients are treated by a single hospital, our competition index takes the value zero, whereas when patients are split equally between $n^{i}$ hospitals, it takes the value $1-1 / n^{i}$. As the number of hospitals tends to infinity, our index converges to one.

The competition measure at the hospital level is obtained by averaging the indexes of all patients within the hospital and it is given by $C_{j}=1-H H I^{j}$, where:

$$
H H I^{j}=\frac{1}{N_{j}} \sum_{i \in j} H H I_{i}
$$

The larger this measure, the more de-concentrated is the local healthcare market of the hospital.

\section{Empirical strategy}

We want to assess whether the reform has led to a decrease in mortality due to an increase in local competition between hospitals. For that purpose, we examine whether the effect of our local competition index on mortality has evolved towards more negative values after the reform. This approach is akin to difference in differences since it amounts to evaluate whether mortality has decreased faster in hospitals located in more competitive markets than in those located in less competitive markets. Identification comes from spatial variations in the competitiveness of local markets following papers studying the UK reform (Cooper et al., 2011; Gaynor et al., 2013). Nevertheless, the French healthcare system is characterized by differences in reimbursement rules and managerial autonomy across sectors and results for hospitals under different funding regimes can be contrasted. This is akin to a triple difference approach that makes it possible to identify the importance of reimbursement rules and managerial autonomy that are set prior to 2004 on the competition effect of the reform. 
We estimate the competition effect of the reform on mortality using a stratified Cox duration model. This model allows for censorship when patients return home or are transferred, as well as hospital unobserved heterogeneity through the inclusion of unspecified hospitalspecific baseline hazards (see Ridder and Tunali, 1999, for more details). We evaluate both the long-run effect of the reform and its average effect over our whole period of study. The long-run effect is assessed using only data for the two years 1999 and 2011. The hazard function of the Cox competitive risk model can be written as:

$$
\theta\left(\ell \mid X_{i, t}\right)=\lambda_{h(i)}(\ell) \mu\left(X_{i, t}\right)
$$

where $\ell$ is the duration since admission, $h(i)$ is the hospital where patient $i$ is admitted, $\lambda_{h}(\ell)$ is the baseline hazard in hospital $h$ which is left unspecified, and $\mu\left(X_{i, t}\right)$ captures the effects of individual and local variables at time $t$ such that:

$$
\begin{aligned}
\log \mu\left(X_{i, t}\right) & =\beta_{1} 1_{\{t=2011\}}+\beta_{2} \operatorname{Pri}_{h(i)} * 1_{\{t=2011\}}+\beta_{3} C_{h(i), t}+\beta_{4} C_{h(i), t} * \operatorname{Pri}_{h(i)} \\
& +\beta_{5} C_{h(i), t} * \operatorname{Pri}_{h(i)} * 1_{\{t=2011\}}+\beta_{6} C_{h(i), t} * \operatorname{Pub} b_{h(i)} * 1_{\{t=2011\}} \\
& +Z_{i} \beta_{7}
\end{aligned}
$$

where $C_{h, t}$ is the competition index for hospital $j$ at time $t, \operatorname{Pr}_{h}$ is a dummy equal to one if the hospital is in the private sector (ie. for-profit) and zero otherwise, $P u b_{h}$ is a dummy equal to one if the hospital is in the public sector and zero otherwise, $1_{\{\cdot\}}$ is the indicator function, and $Z_{i}$ is a set of patient variables. ${ }^{11}$

The main coefficients of interest, $\beta_{5}$ and $\beta_{6}$, measure the competition effects of the reform on hospitals in the private and public sectors, respectively. Variables used as controls include a dummy for year 2011, its interaction with a dummy for private status, the competition index, its interaction with a dummy for private status as well as individual characteristics related to case-mix (interactions between sex and age brackets, detailed information on secondary diagnoses and comorbidities, average income in the municipality) and procedure (treatment with angioplasty).

Coefficients are identified thanks to variations of variables in the within-hospital dimension. In particular, for our main coefficients of interest, identification comes from both the

\footnotetext{
${ }^{11}$ Note that we do not include a non-interacted dummy for hospital status in the specification since its effect is not identified separately from hospital-specific baseline hazard functions.
} 
time variations in the dummy for year 2011 and the spatial variations of the competition index. The specification can be estimated by maximizing the stratified partial likelihood that makes hospital-specific baseline hazards disappear. Thanks to this estimation procedure, estimated coefficients of explanatory variables are not affected by the incidental parameter problem as could be those obtained when directly estimating a Cox model with hospital fixed effects. ${ }^{12}$

Our empirical strategy departs from the usual practice that consists in estimating linear probability models for mortality within a given duration interval, typically 30 days. What occurs after censorship within that interval is usually ignored and this can lead to biases. For instance, if patients in more competitive markets are sent home when they are more likely to die to preserve good statistics on mortality in hospitals, the effect of local competition on mortality is understated. The stratified Cox duration model deals with this issue and biases are avoided as long as durations before death, home return and transfers are independent conditionally on the unspecified hospital baseline hazards and explanatory variables that include the individual characteristics of patients, a possible treatment with angioplasty and our local competition index.

A usual concern is that the competition index might be endogenous because patients might choose their hospital depending on the mortality rate (Bresnahan, 1989). Endogeneity issues are properly taken into account if hospital choices of patients depend on individual explanatory variables and the flexible form of hospital unobserved heterogeneity that is introduced, but not on individual or hospital time-specific shocks that may affect mortality. An alternative strategy consists in constructing a local competition index that is based only on quantities considered to be exogenous. We present in Section 5 robustness checks when constructing the competition index using predicted flows of patients instead of the actual flows as proposed by Kessler and McClellan (2000).

In additional regressions, we assess in more details the role of funding regimes in the public sector by comparing the competition effect of the reform separately for non-profit, university and non-teaching public hospitals. The comparison between non-profit and stateowned hospitals (university and non-teaching) provides information on the role of managerial autonomy. Contrasting results obtained for university and non-teaching public hospitals makes it possible to assess whether there is an influence of having teaching activities. ${ }^{13}$

\footnotetext{
12 Since the number of patients in some hospitals used for the identification of the corresponding hospital fixed effects is rather small, an incidental parameter problem may occur. That problem does not arise with a stratified Cox duration model as the effects of explanatory variables are estimated by maximizing the stratified partial likelihood that does not involve hospital-specific baseline hazards (see Ridder and Tunali, 1999). This is similar to a withinhospital estimation in a linear context.

${ }^{13}$ As university hospitals are on average larger than non-teaching public hospitals, differences in results between these two types of hospitals may be due not only to teaching activities but also to size effects such that larger hospitals are more or less competitive after the reform.
} 
We also evaluate the average effect of the reform using data covering all the years within the 1999-2011 period. The reform occurs in 2005 in the private sector and we thus consider that the post-reform period for for-profit hospitals spans from 2005 onwards. By contrast, the reform is implemented gradually between 2004 and 2008 in the public sector and we distinguish for public hospitals the 2004-2007 transition period from the period spanning from 2008 onwards during which the reform is fully implemented. The specification is still given by (1) but the influence of explanatory variables is now:

$$
\begin{aligned}
\log \mu\left(X_{i, t}\right) & =\gamma_{1} t+\gamma_{2} 1_{\{t \geq 2004\}} * P u b_{h(i)} \\
& +\gamma_{3} 1_{\{t \geq 2008\}} * P u b_{h(i)}+\gamma_{4} 1_{\{t \geq 2005\}} * \operatorname{Pri}_{h(i)} \\
& +\gamma_{5} C_{h(i), t}+\gamma_{6} C_{h(i), t} * t+\gamma_{7} C_{h(i), t} * \operatorname{Pri}_{h(i)} \\
& +\gamma_{8} C_{h(i), t} * \operatorname{Pri}_{h(i)} * 1_{\{t \geq 2005\}} \\
& +\gamma_{9} C_{h(i), t} * P u b_{h(i)} * 1_{\{t \geq 2004\}}+\gamma_{10} C_{h(i), t} * P u b_{h(i)} * 1_{\{t \geq 2008\}} \\
& +Z_{i} \gamma_{11}
\end{aligned}
$$

where $t$ is the time trend.

Our main coefficients of interest include $\gamma_{8}$ which captures, for for-profit hospitals, the average competition effect of the reform from 2005 onwards, as well as $\gamma_{9}$ and $\gamma_{10}$ that capture, for hospitals in the public sector, respectively the average competition effect of the reform since its start in 2004 and the additional effect once the reform has been completed in 2008. Hence, for these hospitals, the competition effect of the reform is $\gamma_{9}$ over the 2004-2007 period and it changes to $\gamma_{9}+\gamma_{10}$ from 2008 onwards.

Controls in this alternative specification include a time trend, dummies for interactions between time periods and hospital statuses, the competition index, its interactions with the time trend and the dummy for private status, as well as the same individual variables as in specification (2) to capture the effects of case-mix and treatment with an angioplasty. As previously, we also conduct separate regressions by hospital status to identify the effects of having managerial autonomy and teaching activities. Robustness checks dealing with endogeneity issues are conducted as before by replacing the competition index by its predictor using predicted flows of patients instead of the actual flows. 


\section{Data and Preliminary Statistics}

\section{IV.1. Data}

We use the exhaustive data on stays in French hospitals provided by the Programme de Médicalisation des Systèmes d'Information over the 1999-2011 period, and restrict our attention to patients admitted to a hospital for an AMI. Because heart attacks before the age of 35 are usually related to a heart dysfunction, we consider only patients aged 35 and over, which is in line with the OMS definition. Stays with duration coded zero (4.6\% of observations) are excluded.

The resulting sample includes 870,549 stays for mainland France with an average of 66,965 per year. ${ }^{14}$ Hospital admissions occur for patients coming from home (80.5\%), from another hospital (18.9\%), or from another service of the same hospital $(0.6 \%)$.

As we cannot keep track of patients when they are transferred to another hospital or service, we restrict our sample to patients who come from their place of residence. We thus discard $19.5 \%$ of observations, which makes the sample size drop to 704,509 stays with an average of 54,193 stays per year.

We have information on the age and sex of patients, as well as detailed information on co-morbidities (i.e. pre-existing conditions), secondary diagnoses and treatment procedures. Detailed co-morbidities and diagnoses are related to the way of life (smoking, alcoholism, obesity, hypertension), chronic health problems (diabetes, conduction diseases, history of coronary disease) and disease complications (renal failure, heart failure). We know whether patients were treated or not with an angioplasty.

We also have the municipality code of residence and we use it to recover the municipality household median income in 2000 from fiscal data. This measure is used as a proxy for patients' social background that may influence their probability of death.

Finally, our competition index is computed on the whole sample of patients in mainland France. We have the municipality code for both the patients' place of residence and the location of hospitals. ${ }^{15}$ We match these codes with an additional dataset containing the coordinates of the town hall and compute the distance between patients and hospitals as crow flies using these coordinates.

We delete $4.12 \%$ of observations for which information is missing or miscoded, and end up with 675,469 stays with an average of 51,959 stays per year, with $20.4 \%$ of stays being in for-

\footnotetext{
${ }^{14}$ We exclude from the analysis patients and hospitals from DOM-TOM and Corsica, as well as patients from foreign countries, as they are characterized by very specific healthcare.

15 There are around 36,000 municipalities in mainland France. There are two large groups of establishments, one in Paris (called Assistance Publique - Hôpitaux de Paris) and the other one in Marseille (called Assistance Publique - Hôpitaux de Marseille), for which we do not have a specific municipality code for each establishment. We therefore attribute them the municipality code of the first district in their respective city.
} 
profit hospitals, $3.4 \%$ in non-profit hospitals, and $76.2 \%$ in public hospital $(27.6 \%$ in university hospitals and $48.6 \%$ in non-teaching hospitals). The type of discharge is also reported: death $(7.2 \%)$, home return $(61.0 \%)$, transfer to another service $(2.0 \%)$ and transfer to another hospital (29.8\%). As we cannot follow patients when they are discharged, we study patients during their stay within the hospital. We focus on discharge due to death and treat all other discharges as right censored.

\section{IV.2. Preliminary statistics}

We first briefly present descriptive statistics over the whole 1999-2011 period by hospital status, which are reported in Table 1. They show that non-teaching public and non-profit hospitals have the largest proportions of male and female patients above 85 , old individuals being those who are the most fragile and the most likely to die from a heart attack. There is no clear pattern for secondary diagnoses as, for instance, non-teaching public and non-profit hospitals are characterized by the largest proportions of heart failure and conduction disease, but vascular disease and smoking problems are the most frequent in, respectively, for-profit and university hospitals. The use of innovative procedures is the most widespread in for-profit and university hospitals where the proportions of patients treated with an angioplasty (possibly with stent) are respectively $61 \%$ and $57 \%$, compared to $48 \%$ for non-profit hospitals and only $28 \%$ for nonteaching hospitals. The average length of stays is the largest in non-profit and non-teaching hospitals at respectively 7.9 and 7.7 days, and the smallest in for-profit hospitals at 7.0 days, while university hospitals occupy an intermediate position at 7.5 days. Finally, the mortality rate within 30 days is the largest in non-teaching and non-profit hospitals at respectively 8.6 and 7.7 percent, and it is the lowest in for-profit and university hospitals at respectively 5.2 and 5.7 percent.

\section{[ Insert Table 1]}

We then turn to stylized facts on the evolution of some quantities of interest over the 1999-2011 period: the competition index, the length of stay and the mortality rate. As shown by Figure 2, patients tend to be more concentrated over time since our competition index decreases from 0.52 to 0.46 . There is a positive jump of 0.03 in 2004 when the reform began to be implemented and we could check that it occurs because of changes in hospital concentration in the Paris region where a large group of hospitals (called APHP) is located. 
The length of stay decreased continuously from 8.3 to 6.9 days and there were not any change in the pace of decrease after the reform. Besides, there were significant differences in average length of stay across hospital statuses at the beginning of the period: in 1999, the average length of stay was the largest for non-profit and non-teaching public hospitals at respectively 8.8 and 8.7 days. It was the lowest for university and for-profit hospitals at respectively 8.2 and 7.6 days. The average length of stay decreased over the period for every hospital status but not at the same pace. In 2011, non-profit, university and non-teaching public hospitals ended up having similar average length of stay at respectively 7.1, 6.9 and 6.8 days. For-profit hospitals had the lowest at 6.3 days but, overall, differences between for-profit and other hospitals slightly decreased.

\section{[ Insert Figure 2]}

The profile of mortality rate within 30 days by hospital status over the 1999-2011 period is represented in Figure 3. It shows that the mortality rate decreased regularly for university, nonteaching public and for-profit hospitals. Non-profit hospitals rather exhibited a mortality rate which temporarily increased over the 2000-2003 period before decreasing sharply at the beginning of the reform and then fluctuating towards lower values. Interestingly, differences between hospital statuses with high mortality rates (non-teaching public and non-profit) and those with low mortality rates (university and for-profit) decreased after 2003. In particular, the difference in mortality rates between for-profit and non-teaching public hospitals was as high as 3.8 points in 2003 , but it decreased to 2.9 points in 2011. In this work, we are interested in evaluating whether the competition effect of the reform has led to a decrease in mortality rate for some hospital statuses.

\section{[ Insert Figure 3]}

We first implement a descriptive approach which consists in assessing whether the slope of the relationship between the mortality rate and the competition index at the hospital level decreased after the reform. For that purpose, we plot the average mortality rate within 30 days against the average competition index at the hospital level for the 2001-2003 and 2009-2011 periods by hospital status. For each period, we limit our attention to hospitals admitting at least 10 patients for plots to be meaningful. Figure 4 shows that, when considering the 2001-2003 period, the slope is close to zero for all hospital statuses except non-profit, for which it is 
positive. There is no clear-cut difference with the slope after the reform except for non-profit hospitals and slightly for non-teaching public hospitals for which the slope becomes negative. This suggests that there would be a competition effect of the reform for non-profit hospitals but not for others. Nevertheless, it is necessary to rely on an econometric analysis to assess whether this result still holds when taking into account factors that can affect mortality.

\section{[ Insert Figure 4]}

\section{Results}

We now turn to the results on the competition effect of the reform on mortality that we obtain when estimating stratified Cox models.

\section{V.1. Long-run effect of the policy}

We first comment the results obtained for the long-run impact of the policy with specification (2) using the years 1999 and 2011 only. Estimated coefficients of individual variables have the expected sign: ${ }^{16}$ patients die less when they are males, young, and have received innovative treatment. While some secondary diagnoses have a positive effect on mortality, others have a negative effect and this can be explained by a better monitoring of the corresponding patients (see Gobillon and Milcent, 2013, for more details).

Results obtained for the competition effect of the reform for the full sample (Table 2, column (1) show that its estimate is significant neither in the private sector nor in the public one. This is confirmed by separate regressions for the two sectors which estimates are reported in columns (2) and (3). These estimates are not in line with theoretical models predicting a positive relationship between competition and quality. However, as explained in Section 2, these results were expected in the French context. Indeed, for for-profit hospitals, the reform only increased the pool of potential competitors by including hospitals in the public sector, but public hospitals may not have diverted patients from for-profit hospitals, possibly because they do not have enough incentives or means to compete for patients on quality, or because for-profit hospitals are on specific segments of the healthcare market.

\section{[ Insert Table 2]}

\footnotetext{
${ }^{16}$ Estimated coefficients obtained for the full sample are reported in Appendix Table C1.
} 
Results on pooled public hospitals mask some heterogeneity in the competition effect of the reform across hospital statuses as shown by columns (4)-(6). The reform is found to have the expected negative competition effect on mortality for non-profit hospitals. This is consistent with the theoretical argument that non-profit hospitals would compete more on quality in more competitive markets after the reform. For university hospitals, we obtain that the reform has a positive but non-significant competition effect on mortality. This is consistent with a lack of incentives for university hospitals to compete for patients. Indeed, they benefit from additional funding for teaching activities that loosen their budget constraint both before and after the reform. Moreover, because of their reputation due to good high-tech equipment and highlytrained physicians, they already captured their potential pool of patients before the reform.

We here find a non-significant negligible negative effect for non-teaching hospitals. It seems that these hospitals are unable to improve quality to be more competitive and attract patients in de-concentrated markets after the reform. Labour rigidities related to the civil servant status of workers probability make it difficult to have an efficient management of the medical staff and to implement strong adjustments in the facilities. Overall, results suggest that managerial autonomy would matter.

\section{V.2. Distinction between the transition and post-reform periods}

We then investigate the average competition effect of the reform after its implementation over the 1999-2011 period by estimating specification (3) and results are reported in Table 3. As previously, we find that the reform has no average competition effect when sectors are pooled together and when considering the private sector only (columns 1 and 2). The estimated effect for the public sector is now negative but significant at the $10 \%$ level only (column 3), and there is again some heterogeneity in the competition effect across hospital statuses. We obtain a negative effect on mortality for non-profit hospitals after the full implementation of the reform (column 4) although to a lesser extent than previously since the estimated effect is now $-0.133-0.974=$ 1.107. This slight change can be explained by the fact that the competition effects of the reform after its full implementation are here measured by contrasting the 2008-2011 period with the 1999-2003 period, whereas previously we contrasted only the most remote years 2011 and 1999. As expected, the competition effect of the reform is very close to zero for university hospitals (column 5). For non-teaching public hospitals, we find that the estimated competition effect on mortality is significantly negative during the transition period (column 6). There is no sizable change in the effect, which remains quite small, when the reform is fully implemented. 


\section{[ Insert Table 3 ]}

\section{V.3. A quantification of the competition effect of the reform}

We now propose a counterfactual exercise to quantify the order of magnitude for the competition effects of the reform. Once the coefficients and hospital hazards of the stratified Cox model have been estimated, we compute the average probability of dying within 5 days after the reform by hospital status and for all hospitals pooled together. This probability can be contrasted with the one corresponding to the counterfactual situation where there is no competition effect of the reform, which is obtained by fixing the related coefficients to zero $\left(\beta_{5}\right.$ and $\beta_{6}$ for specification 2 , and $\gamma_{8}, \gamma_{9}$ and $\gamma_{10}$ for specification 3). We consider the difference in the probability of death within 5 days as our measure of the competition effect of the reform, and the standard deviation, confidence interval and level of significance of its estimator are obtained by bootstrap using 100 replications. Technical details of our computations are relegated to Appendix B.

Results reported in Table 4 show that, in the case of specification (2), the probability of death within 5 days in 2011 is $2.8 \%$ in non-profit hospitals but it would be larger by as much as 5.4 points if there had not been any competition effect of the reform, the confidence interval of this difference being rather narrow at $[4.46 ; 6.32]$. For university and non-teaching public hospitals, there are much smaller differences in the probability of death associated with the competition effect of the reform since they amount respectively to 0.3 and 0.1 points. For forprofit hospitals, the corresponding difference is of the opposite sign but it remains rather small at -0.6 points. The differences for these three types of hospitals are statistically not significant. Importantly, we also computed the average across hospital statuses of the differences in the probability of death and it is very small at 0.2 points and not significant. This occurs because patients in non-profit hospitals, for which the competition effect would be very large, represent only $3.0 \%$ of patients in 2011. Overall, the competition effect of the reform would be negligible.

It is possible to conduct a similar analysis when considering specification (3) and it leads to similar conclusions. In particular, the probability of death within 5 days over the 2008-2011 period is $3.4 \%$ for non-profit hospitals but it would be larger by 3.5 points if there had not been any competition effect of the reform, the confidence interval being $[2.37 ; 4.53]$. For all the other hospitals statuses, the difference in the probability of death related to the competition effect of the reform is close to zero and not significant. As patients in non-profit hospitals only represent $3.2 \%$ of patients over the $2008-2011$ period, it is not surprising to find as before that the average 
across hospital statuses of the differences in the probability of death is as small as 0.2 points and not significant, which is in line with a negligible competition effect of the reform.

[ Insert Table 4]

\section{V.4. Robustness checks when using alternative competition indices}

\section{Alternative definitions of local competition indices}

As there is a debate on the right index to use in order to properly capture local competition, we conduct robustness checks using alternative definitions for the competition index. More precisely, the willingness of a hospital to compete for patients may not be related that much to the distribution of patients across local hospitals but rather to the amount of patients located around who are not admitted in the hospital but that could potentially be captured. We thus alternatively use the LOgit Concentration Index (LOCI) introduced by Akosa, Gaynor and Vogt (2006) which is shown to be a relevant measure of local competition in quality for potential patients in a fixed-price setting by Bynum, Colla and Skinner (2016). We consider again a maximum scope of 30 kilometres for local competition for a better comparison with our main index. Note that the LOCI varies in the same direction as our competition index since the LOCI increases when competition increases. The correlation between the two indices computed at the patient level over the whole period is 0.42 .

We assess to what extent the results we obtained on the long-term competition effect of the policy using only the years 1999 and 2011 are robust when considering the LOCI index. Estimated coefficients of regressions by hospital status are reported in Table 5. Results are consistent with our main findings since the estimated competition effect of the reform on mortality is negative and significant for non-profit hospitals, negative and slightly significant for non-teaching public hospitals, and not significant for hospitals with other statuses. When conducting estimations over the whole 1999-2011 period, estimated coefficients are again mostly in line with our main conclusions. Some slight differences are that, for non-profit hospitals, the negative competition effect of the reform on mortality during the transition period is now larger in absolute terms and significant at the $10 \%$ level, and the additional effect during the postreform period is now comparatively smaller in absolute terms.

[ Insert Table 5 ] 


\section{Local competition index constructed from predicted patient flows}

There may be an endogeneity concern when estimating the effect of our benchmark competition index on mortality since this index might be correlated with unobserved patient characteristics not taken into account in our estimations (see for instance Bresnahan, 1989). Indeed, patients can choose freely among hospitals in France and are likely to select one using the information given by their physician, the press (as a ranking of hospitals is published every year), family and relatives. It is possible that patients most likely to die are admitted to the best hospitals that are the only ones able to treat them. These hospitals may be located in large cities where there is a considerable supply of good surgeons, and large cities are often more competitive local markets. This would lead to a positive bias on the estimated coefficient of our competition index. On the other hand, it is also possible that some high-quality hospitals dominate locally and run the competition out of their local market which would end up being rather concentrated. These hospitals may treat the patients the most likely to die and this would cause a negative bias on the estimated coefficient of our competition index.

Consistently with the literature, we assess whether the existence of unobservable patient characteristics might bias our estimated coefficients by constructing an alternative competition index from predicted flows of patients to hospitals (see Kessler and McClellan, 2000). We first estimate a logit model of hospital choice, where the explanatory variables are the distance from the patient's municipality of residence to the municipality of the hospital where she is admitted, dummies for hospital statuses and interactions between age bracket and gender dummies. From these estimates, we deduce the probability of each patient going to each hospital, and then compute the predicted number of patients in every hospital. We finally construct a new set of patients' HHI indexes within $30 \mathrm{~km}$ using predicted numbers of patients in every hospital instead of actual ones. Our alternative competition index for a given hospital is one minus a weighted average of these HHI computed across all patients, where the weight for a given patient is her probability of going to the hospital.

It is possible to check that our initial competition index and the predicted competition index are positively related since their correlation is 0.38 . Table 5 shows that, when considering the long-term competition effect of the policy using the years 1999 and 2011 only, results for the stratified Cox model obtained when using the predicted competition index are broadly consistent with our initial results. While the competition effect is of similar magnitude for non-profit hospitals, it is now significant at the $1 \%$ level. When turning to the estimations over the whole 1999-2011 period, we get similar results for non-profit, university and for-profit hospitals when using our initial and predicted competition indexes. Results are slightly different for non-teaching 
hospitals when using our predicted competition index, since the competition effect of the reform after the transition period is now negative and significant. Nevertheless, as before, the magnitude of this effect is very small.

\section{V.5. Robustness checks when using alternative specifications}

We assess to what extent it is important to take into account unobserved hospital heterogeneity in a flexible way. For that purpose, we compare our main estimates of the competition effect of the reform with those obtained with a standard Cox model without and with hospital fixed effects.

First consider the long-run effect of the reform obtained from years 1999 and 2011 only. As shown in Table C2, the magnitude of the competition effect for non-profit hospitals is rather robust across specifications. By contrast, a positive significant effect at the $10 \%$ level is found for university hospitals with the standard Cox model without hospital fixed effects. Estimated coefficients obtained when introducing hospital fixed effects are in line with those obtained with the stratified Cox model. Overall, our results suggest that it is important to take unobserved hospital heterogeneity into account to avoid estimation biases. The use of a Cox model with hospital fixed effects rather than a stratified Cox model with fully flexible hospital hazards seems enough for that purpose, but we will see below that there are estimated specifications for which this is not the case. ${ }^{17}$

Now consider the average effect of the reform over the whole period. Results reported in Table C3 show that estimates are quite different when estimating a standard Cox model in which no unobserved hospital heterogeneity is taken into account. Indeed, the negative competition effect found for non-profit hospitals is lower and the reform now has a positive effect on mortality significant at the $10 \%$ level for university hospitals. Estimates for the Cox model with hospital fixed effects are closer to those of the stratified Cox model, but the negative competition effect of the reform for non-teaching hospitals over the 2004-2007 period is smaller and nonsignificant. Overall, the estimates obtained with alternative Cox specifications confirm that controlling for hospital unobserved heterogeneity is important to avoid biases when evaluating the competition effect of a policy, but they also suggest that this should be done in a flexible way. Interestingly, the results for a linear probability model for mortality within 30 days projected in the within-hospital dimension are in line with those of the stratified Cox model.

\footnotetext{
${ }^{17}$ Note that results obtained with OLS and within estimations are both qualitatively similar to those obtained with the stratified Cox model.
} 


\section{Conclusion}

Health expenditures are growing in most countries and governments are looking for ways to control spending while improving health care. There is a growing interest in competition among hospitals as it may improve quality in fixed-price markets. Initial results on the effect of local competition on quality were obtained for privately-run providers in the US in a context where there was already competition among hospitals. More recent evidence is on the effect of a pro-competition reform of the UK healthcare system on state-owned institutions. The government made a series of reforms to give more managerial and financial autonomy to these institutions. Before the reforms, the hospital sector involved only public providers and was strictly regulated. Today, there is an emerging private sector on specific segments of the healthcare market.

So far, studies have focused only on the competition effects in a single sector. In France, the healthcare market was and is still composed of public and private hospitals. The reform gradually introduced in France over the 2004-2008 period did not introduce any change in the structure of this market. In this paper, we study the effect on hospital quality of this procompetition reform by hospital status. We assess whether hospital quality in more competitive markets increased more after the reform than that in less competitive markets, respectively for for-profit, public (university or non-teaching) and non-profit hospitals. For that purpose, we estimate a Cox model for duration before death stratified by hospital on an exhaustive dataset of heart attack patients admitted in a hospital during the 1999-2011 period.

We show that the reform had a significant and sizable negative competition effect on mortality for non-profit hospitals but not for hospitals with other statuses. This means that the decline in mortality was larger for non-profit hospitals located in places where there is greater competition than for those in less competitive markets. These results show that both the initial funding system and management matter to obtain a positive competition effect of the reform on hospital quality. Ours results are robust to taking into account the endogeneity of patient hospital choice when constructing our competition index.

The literature suggests that one channel through which local competition may affect hospital quality is a change in management quality, but other mechanisms are worth exploring such as adjustments in technological equipment and quality of surgeons. There are also dimensions of hospital quality other than mortality that could be investigated such as waiting time, comfort, medicine, attention paid by the staff and more generally the well-being of patients. These questions are left for future research. 


\section{References}

Akosa Y., Gaynor M., and W. Vogt (2006), "A Competition Index for Differentiated Products Oligopoly with an Application to Hospital Markets", Working Paper, Carnegie Mellon University.

Bloom N., Cooper Z., Gaynor M., Gibbons S., Jones S., McGuire A., Moreno-Serra R., Propper C., Van Reenen J. and S. Seiler (2011), "In defence of our research on competition in England's National Health Service", The Lancet, 378(9809), pp. 2064-2065.

Bloom N., Propper C., Seiler S. and J. Van Reenen (2015), "The Impact of Competition on Management Quality: Evidence from Public Hospitals", Review of Economic Studies, 82(2), pp. 457489.

Bresnahan T. (1989), "Empirical Studies of Industries with Market Power", in Handbook of Industrial Organization, Vol. 2, Richard Schmalensee and Robert Willig (eds.), Chapter 17, pp. 1011-1057. Amsterdam and New York: Elsevier Science/North-Holland.

Bynum J., Colla C. and J. Skinner (2016), "Hospital competition, quality, and expenditures in the U.S. Medicare population”, Working Paper.

Canoy M. and W. Sauter (2009). Hospital mergers and the public interest: Recent developments in the Netherlands, Tilburg University.

Chou S.Y., Deily M., Li S. and Y. Lu (2014), "Competition and the impact of online report cards", Journal of Health Economics, 34, pp. 42-58.

Cookson R., Laudicella M. and P. Li Donni (2013), "Does hospital competition harm equity? Evidence from the English National Health Service", Journal of Health Economics, 32, pp. 410-422.

Cooper Z., Gibbons S., Jones S. and A. McGuire (2011), "Does hospital competition save lives? Evidence from the English patient choice reforms", The Economic Journal, 121, pp. F228- F260.

Cooper Z., Gibbons S. and M. Skellern (2016), "Does Competition from Private Surgical Centres Improve Public Hospitals' Performance? Evidence from the English National Health Service", CEP Working Paper 1434.

Gaynor M. (2007), "Competition and Quality in Health Care Markets" in Foundations and Trends ${ }^{\circledR}$ in Microeconomics, 2(6), pp. 441-508. Norwell: now publisher inc.

Gaynor M. and R. Town (2013), "Competition in Health Care Markets", in Handbook of Health Economics Vol. 2, Mark Pauly, Thomas Mcguire and Pedro Barros (eds.), Chapter 9, pp. 499637. Amsterdam and New York: Elsevier Science/North-Holland.

Gaynor M., Moreno-Serra R. and C. Propper (2013), "Death by market power: reform, competition and patient outcomes in the National Health Service", American Economic Journal: Economic Policy, 5(4), pp. 134-166.

Gaynor M., Propper C. and S. Seiler (2016), "Free to Choose? Reform and Demand Response in the English National Health Service", American Economic Review, forthcoming. 
Gobillon L. and C. Milcent (2013), "Spatial Disparities in Hospital Performance", Journal of Economic Geography, 13(6), pp. 1013-1040.

Gobillon L. and C. Milcent (2016), "Evaluating the effect of ownership status on hospital quality: the key role of innovative procedures", Annals of Economics and Statistics,121-122, pp. 161-186.

Gowrisankaran G. and R. Town (2003), "Competition, Payers, and Hospital Quality", Health Services Research, 38(6), pp. 1403-1422.

Kessler D. and M. McClellan (2000), "Is hospital competition socially wasteful?", Quarterly Journal of Economics, 115(2), pp. 577-615.

Kessler D. and J. Geppert (2005), "The Effects of Competition on Variation in the Quality and Cost of Medical Care", Journal of Economics \& Management Strategy, 14(3), pp. 575-589.

McClellan M. and D. Staiger (1999), "The Quality of Health Care Providers", NBER Working Paper 7327.

O'Keeffe and M. Skellern (2015), "Do altruistic hospitals and profit-maximising hospitals respond differently to competition?", Working Paper.

Ridder G. and I. Tunali (1999), "Stratified partial likelihood estimation", Journal of Econometrics, 92(2), pp. 193-232. 


\section{Table 1. Summary Statistics by Hospital Status}

\begin{tabular}{|c|c|c|c|c|c|c|c|c|c|c|}
\hline \multirow[t]{2}{*}{ Variable } & \multicolumn{2}{|c|}{ All hospitals } & \multicolumn{2}{|c|}{$\begin{array}{l}\text { University } \\
\text { hospitals }\end{array}$} & \multicolumn{2}{|c|}{$\begin{array}{l}\text { Non-teaching } \\
\text { public hospitals }\end{array}$} & \multicolumn{2}{|c|}{$\begin{array}{c}\text { Non-Profit } \\
\text { Hospitals }\end{array}$} & \multicolumn{2}{|c|}{$\begin{array}{c}\text { For-Profit } \\
\text { hospitals }\end{array}$} \\
\hline & $\begin{array}{c}\text { Mean } \\
(\%)\end{array}$ & Std & $\begin{array}{c}\text { Mean } \\
(\%)\end{array}$ & Std & $\begin{array}{c}\text { Mean } \\
(\%)\end{array}$ & Std & $\begin{array}{c}\text { Mean } \\
(\%)\end{array}$ & Std & $\begin{array}{c}\text { Mean } \\
(\%)\end{array}$ & Std \\
\hline Female, 55-65 & 3.00 & 0.17 & 3.31 & 0.18 & 2.80 & 0.17 & 2.97 & 0.17 & 3.05 & 0.17 \\
\hline Female, 65-75 & 6.24 & 0.24 & 6.02 & 0.24 & 6.36 & 0.24 & 6.23 & 0.24 & 6.27 & 0.24 \\
\hline Female, 75-85 & 11.43 & 0.32 & 9.59 & 0.29 & 12.98 & 0.34 & 12.63 & 0.33 & 10.30 & 0.30 \\
\hline Female, more than 85 & 8.93 & 0.29 & 6.80 & 0.25 & 11.55 & 0.32 & 10.21 & 0.30 & 5.71 & 0.23 \\
\hline Male,35-55 & 18.12 & 0.39 & 21.94 & 0.41 & 15.58 & 0.36 & 16.99 & 0.38 & 18.72 & 0.39 \\
\hline Male,55-65 & 15.13 & 0.36 & 17.12 & 0.38 & 13.00 & 0.34 & 14.94 & 0.36 & 17.26 & 0.38 \\
\hline Male,65-75 & 15.37 & 0.36 & 15.42 & 0.36 & 14.45 & 0.35 & 14.98 & 0.36 & 17.51 & 0.38 \\
\hline Male,75-85 & 13.90 & 0.35 & 12.40 & 0.33 & 14.65 & 0.35 & 13.37 & 0.34 & 14.39 & 0.35 \\
\hline Male, more than 85 & 4.96 & 0.22 & 3.88 & 0.19 & 6.02 & 0.24 & 5.05 & 0.22 & 4.03 & 0.20 \\
\hline Alcohol problem & 1.30 & 0.11 & 1.33 & 0.12 & 1.43 & 0.120 & 0.99 & 0.10 & 1.04 & 0.10 \\
\hline Smoking problem & 13.95 & 0.35 & 18.07 & 0.39 & 11.97 & 0.33 & 9.81 & 0.230 & 13.48 & 0.34 \\
\hline Obesity & 8.28 & 0.28 & 10.33 & 0.30 & 7.17 & 0.26 & 7.78 & 0.27 & 8.09 & 0.27 \\
\hline Diabetes & 17.45 & 0.38 & 16.66 & 0.37 & 17.64 & 0.38 & 19.00 & 0.39 & 17.86 & 0.38 \\
\hline Hypertension & 35.64 & 0.48 & 35.27 & 0.48 & 34.82 & 0.48 & 39.89 & 0.49 & 37.37 & 0.48 \\
\hline Renal failure & 6.92 & 0.25 & 6.99 & 0.26 & 7.38 & 0.26 & 8.11 & 0.27 & 5.58 & 0.23 \\
\hline Vascular disease & 5.45 & 0.23 & 4.38 & 0.21 & 5.00 & 0.22 & 6.14 & 0.24 & 7.83 & 0.27 \\
\hline $\begin{array}{l}\text { Peripheral arterial } \\
\text { disease }\end{array}$ & 6.21 & 0.24 & 5.91 & 0.24 & 5.89 & 0.24 & 8.63 & 0.28 & 6.96 & 0.26 \\
\hline Other vascular disease & 3.33 & 0.18 & 3.04 & 0.17 & 3.47 & 0.18 & 3.33 & 0.18 & 3.39 & 0.18 \\
\hline Other ischemic disease & 4.61 & 0.21 & 3.76 & 0.19 & 4.07 & 0.20 & 5.36 & 0.23 & 6.91 & 0.25 \\
\hline Heart failure & 16.69 & 0.37 & 14.32 & 0.35 & 19.14 & 0.39 & 19.59 & 0.40 & 13.82 & 0.35 \\
\hline Conduction disease & 21.02 & 0.41 & 17.86 & 0.38 & 22.49 & 0.42 & 23.30 & 0.42 & 21.64 & 0.41 \\
\hline Stent & 43.65 & 0.50 & 57.38 & 0.50 & 27.52 & 0.45 & 48.47 & 0.50 & 60.54 & 0.49 \\
\hline Length Of Stay & 7.57 & 7.09 & 7.49 & 7.66 & 7.87 & 7.16 & 7.70 & 7.11 & 6.98 & 5.94 \\
\hline Mortality rate & 7.02 & 0.26 & 5.68 & 0.23 & 8.60 & 0.28 & 7.76 & 0.27 & 5.15 & 0.22 \\
\hline
\end{tabular}

Note. Std: Standard Deviation. Descriptive statistics computed on the sample of patients aged 35-100 admitted from their place of residence (and not a transfer). 
Table 2. Competition effect of the reform on mortality between 1999 and 2011, Stratified Cox Model estimations

\begin{tabular}{|c|c|c|c|c|c|c|}
\hline \multirow[t]{3}{*}{ Variable } & \multirow{3}{*}{$\begin{array}{l}\text { All hospitals } \\
\text { (1) }\end{array}$} & \multirow{3}{*}{$\begin{array}{l}\text { For-profit } \\
\text { hospitals } \\
\text { (2) }\end{array}$} & \multicolumn{4}{|c|}{ Hospitals in the public sector } \\
\hline & & & & Non-profit & University & $\begin{array}{l}\text { Non- } \\
\text { teaching }\end{array}$ \\
\hline & & & (3) & (5) & (5) & (6) \\
\hline \multirow[t]{2}{*}{ Year 2011} & $-0.236 * * *$ & $-0.054 * * *$ & $-0.217 * * *$ & $-0.687^{* *}$ & $-0.018^{*}$ & $-0.197^{* *}$ \\
\hline & $(0.076)$ & $(0.020)$ & $(0.068)$ & $(0.334)$ & (0.011) & (0.093) \\
\hline Private sector & -0.051 & & & & & \\
\hline * Year 2011 & $(0.181)$ & & & & & \\
\hline \multirow[t]{2}{*}{$\mathrm{C}$} & -0.077 & $-0.166^{* * *}$ & -0.009 & $-0.015^{*}$ & -0.008 & -0.010 \\
\hline & $(0.097)$ & $(0.044)$ & $(0.010)$ & $(0.008)$ & $(0.010)$ & $(0.011)$ \\
\hline \multirow[t]{2}{*}{$\mathrm{C} *$ Private sector } & -0.097 & & & & & \\
\hline & $(0.303)$ & & & & & \\
\hline$C *$ Private sector & -0.384 & -0.305 & & & & \\
\hline * Year 2011 & $(0.360)$ & $(0.354)$ & & & & \\
\hline C * Public sector & -0.034 & & 0.004 & $-1.446^{*}$ & 0.164 & -0.021 \\
\hline * Year 2011 & $(0.111)$ & & $(0.111)$ & $(0.878)$ & $(0.103)$ & $(0.139)$ \\
\hline Patient characteristics & Yes & Yes & Yes & Yes & Yes & Yes \\
\hline $\mathrm{N}$ & 99,628 & 19,962 & 79,666 & 3,192 & 30,234 & 46,240 \\
\hline \multicolumn{7}{|c|}{$\begin{array}{l}\text { Note. } * \text { significant at } 10 \% \text { level; } * * \text { significant at } 5 \% \text { level; } * * * \text { significant at } 1 \% \text { level. Standard errors are reported in } \\
\text { parentheses. C }=1-H H I \text { where HHI is the hospital weighted average of Herfindahl-Hirschman indexes computed for } \\
\text { every patient taking into account establishments within a } 30 \mathrm{~km} \text { radius around her place of residence. All } \\
\text { specifications include as control variables individual characteristics related to case-mix (interactions between sex and } \\
\text { age brackets, detailed information on secondary diagnoses and comorbidities, average income in the municipality) } \\
\text { and procedure (treatment with angioplasty). Their estimated coefficients for the full-sample specification (column } 1 \text { ) } \\
\text { are reported in Table C1. We do not include any private sector dummy because its coefficient is not identified since } \\
\text { the Cox model is stratified by hospital. }\end{array}$} \\
\hline
\end{tabular}


Table 3. Competition effect of the reform on mortality over the 1999-2011 period, Stratified Cox Model estimations

\begin{tabular}{|c|c|c|c|c|c|c|}
\hline \multirow[t]{3}{*}{ Variable } & \multirow{3}{*}{$\begin{array}{c}\text { All hospitals } \\
\text { (1) }\end{array}$} & \multirow{3}{*}{$\begin{array}{l}\text { For-profit } \\
\text { hospitals } \\
\text { (2) }\end{array}$} & \multicolumn{4}{|c|}{ Hospitals in the public sector } \\
\hline & & & All & Non-profit & University & $\begin{array}{l}\text { Non- } \\
\text { teaching }\end{array}$ \\
\hline & & & (3) & (4) & $(5)$ & (6) \\
\hline \multirow[t]{2}{*}{ Linear time trend } & -0.008 & $-0.035^{* * *}$ & $-0.016^{*}$ & -0.044 & $-0.029 *$ & -0.003 \\
\hline & $(0.007)$ & $(0.014)$ & $(0.009)$ & $(0.035)$ & $(0.017)$ & $(0.012)$ \\
\hline Public sector * & $-0.173^{* * *}$ & & $-0.198^{* * *}$ & $-0.294 *$ & $-0.249 * *$ & $-0.142^{* *}$ \\
\hline$($ Year $>=2004)$ & $(0.036)$ & & $(0.049)$ & $(0.177)$ & $(0.099)$ & $(0.061)$ \\
\hline Public sector * & $-0.114 * * *$ & & $-0.157 * * *$ & $-0.563^{* * *}$ & $-0.167^{*}$ & -0.076 \\
\hline$($ Year $>=2008)$ & $(0.032)$ & & $(0.049)$ & $(0.189)$ & $(0.101)$ & $(0.061)$ \\
\hline \multirow[t]{2}{*}{ Private sector } & 0.159 & & & & & \\
\hline & $(0.317)$ & & & & & \\
\hline Private sector $*$ & -0.002 & -0.061 & & & & \\
\hline$($ Year $>=2005)$ & $(0.022)$ & $(0.146)$ & & & & \\
\hline \multirow[t]{2}{*}{$\mathrm{C}$} & -0.038 & $-0.043 * *$ & -0.011 & -0.197 & -0.054 & -0.067 \\
\hline & $(0.059)$ & $(0.017)$ & $(0.061)$ & $(0.409)$ & $(0.125)$ & $(0.073)$ \\
\hline \multirow[t]{2}{*}{$C *$ Linear time trend } & -0.008 & -0.119 & 0.018 & -0.009 & 0.024 & -0.004 \\
\hline & $(0.011)$ & $(0.211)$ & $(0.015)$ & $(0.091)$ & $(0.031)$ & $(0.018)$ \\
\hline \multirow[t]{2}{*}{$C *$ Private sector } & -0.045 & & & & & \\
\hline & $(0.051)$ & & & & & \\
\hline C * Public sector $*$ & -0.077 & & -0.121 & -0.133 & -0.038 & $-0.184 * *$ \\
\hline$($ Year $>=2004)$ & $(0.061)$ & & $(0.081)$ & $(0.469)$ & $(0.174)$ & $(0.088)$ \\
\hline C * Public sector $*$ & -0.077 & & $-0.143 *$ & $-0.964 * *$ & 0.018 & -0.033 \\
\hline$($ Year $>=2008)$ & $(0.055)$ & & $(0.080)$ & $(0.451)$ & $(0.177)$ & $(0.086)$ \\
\hline C * Private sector $*$ & -0.060 & -0.030 & & & & \\
\hline$($ Year $>=2005)$ & $(0.091)$ & $(0.098)$ & & & & \\
\hline Patient characteristics & Yes & Yes & Yes & Yes & Yes & Yes \\
\hline $\mathrm{N}$ & 651,453 & 135,023 & 516,430 & 20,825 & 184,835 & 310,770 \\
\hline
\end{tabular}

Note. * significant at $10 \%$ level; ** significant at $5 \%$ level; *** significant at $1 \%$ level. Standard errors are reported in parentheses. $\mathrm{C}=1-\mathrm{HHI}$ where $\mathrm{HHI}$ is the hospital weighted average of Herfindahl-Hirschman indexes computed for every patient taking into account establishments within a $30 \mathrm{~km}$ radius around her place of residence. All specifications include as control variables individual characteristics related to case-mix (interactions between sex and age brackets, detailed information on secondary diagnoses and comorbidities, average income in the municipality) and procedure (treatment with angioplasty). Their estimated coefficients for the full-sample specification (column 1) are reported in Table C1. We do not include any private sector dummy because its coefficient is not identified since the Cox model is stratified by hospital. 
Table 4. Counterfactual average probabilities of death within 5 days with and without reform

\begin{tabular}{lccccc}
\hline \hline & All & For-profit & Non-profit & University & Non-teaching \\
\hline Between 1999 and 2011 & & & & & \\
\hline No reform & $3.00 \%$ & $2.79 \%$ & $8.22 \%$ & $2.52 \%$ & $3.10 \%$ \\
Reform & $2.84 \%$ & $3.40 \%$ & $2.83 \%$ & $2.19 \%$ & $3.04 \%$ \\
Difference & $-0.16 \mathrm{pts}$ & $0.61 \mathrm{pts}$ & $-5.39 \mathrm{pts}$ & $-0.33 \mathrm{pts}$ & $-0.06 \mathrm{pts}$ \\
& {$[-0.69 ; 0.37]$} & {$[-0.16 ; 1.38]$} & {$[-6.32 ;-4.46]$} & {$[-0.79 ; 0.13]$} & {$[-0.30 ; 0.18]$} \\
\hline Whole 1999-2011 Period & & & & \\
\hline No reform & $2.94 \%$ & $2.00 \%$ & $6.84 \%$ & $2.25 \%$ & $3.58 \%$ \\
Reform & $2.77 \%$ & $2.13 \%$ & $3.39 \%$ & $2.27 \%$ & $3.36 \%$ \\
Difference & $-0.17 \mathrm{pts}$ & $0.13 \mathrm{pts}$ & $-3.45 \mathrm{pts}$ & $0.02 \mathrm{pts}$ & $-0.22 \mathrm{pts}$ \\
& {$[-0.38 ; 0.04]$} & {$[-0.28 ; 0.54]$} & {$[-4.53 ;-2.37]$} & {$[-0.24 ; 0.28]$} & {$[-0.51 ; 0.07]$} \\
\hline \hline
\end{tabular}

Note. pts: points. We compute the average probabilities of death within 5 days after the reform from the stratified Cox model using the estimated coefficients and hospital-specific baseline hazards obtained when estimating the model by hospital status. The probability of death in 2011 is considered when referring to the difference between 1999 and 2011, and the average probability of death over the 2009-2011 period is considered when referring to the whole 1999-2011 period. The computations are detailed in Appendix A. "Reform" refers to the case where all the coefficients are fixed to their estimated values. "No reform" refers to the case where all the coefficients are fixed to their estimated values except the coefficients of interactions between dummies for post-reform periods and the competition index which are fixed to zero. "Difference" refers to the difference between the probabilities of death within 5 days for "Reform" and "No reform". Confidence intervals at the $95 \%$ level computed by bootstrap using 100 replications are reported in brackets under the differences. 
Table 5. Competition effect of the reform on mortality, Stratified Cox Model estimations when using alternative measures of competition

\begin{tabular}{|c|c|c|c|c|c|c|c|c|}
\hline & \multicolumn{4}{|c|}{ LOCI Index } & \multicolumn{4}{|c|}{ Instrumented C Index } \\
\hline & $\begin{array}{l}\text { For- } \\
\text { profit }\end{array}$ & $\begin{array}{l}\text { Non- } \\
\text { profit }\end{array}$ & $\begin{array}{l}\text { Univer- } \\
\text { sity }\end{array}$ & $\begin{array}{c}\text { Non } \\
\text { teaching }\end{array}$ & $\begin{array}{l}\text { For- } \\
\text { profit }\end{array}$ & $\begin{array}{l}\text { Non- } \\
\text { profit }\end{array}$ & $\begin{array}{l}\text { Univer- } \\
\text { sity }\end{array}$ & $\begin{array}{c}\text { Non } \\
\text { teaching }\end{array}$ \\
\hline \multicolumn{9}{|c|}{ Between 1999 and 2011} \\
\hline Index*Private* & 0.238 & & & & 2.739 & & & \\
\hline Year 2011 & $(0.809)$ & & & & $(3.238)$ & & & \\
\hline Index*Public* & & $-1.754^{* *}$ & 0.505 & -0.348 & & $-1.380 * * *$ & 0.125 & -0.399 \\
\hline Year 2011 & & $(0.805)$ & $(0.523)$ & $(0.265)$ & & $(0.523)$ & $(0.141)$ & $(0.858)$ \\
\hline \multicolumn{9}{|c|}{ Whole 1999-2011 period } \\
\hline Index*Private* & 0.026 & & & & 0.049 & & & \\
\hline$($ Year $>=2005)$ & $(0.378)$ & & & & $(0.080)$ & & & \\
\hline Index*Public* & & $-0.400^{*}$ & 0.264 & $-0.213^{* *}$ & & $-0.102 * * *$ & -0.048 & -0.362 \\
\hline$($ Year $>=2004)$ & & $(0.023)$ & $(0.304)$ & $(0.107)$ & & $(0.016)$ & $(0.201)$ & $(0.575)$ \\
\hline Index* Public* & & $-0.626 * * *$ & 0.325 & -0.030 & & $-0.886 * * *$ & 0.125 & $-0.050 * * *$ \\
\hline$($ Year $>=2008)$ & & $(0.015)$ & $(0.326)$ & $(0.107)$ & & $(0.026)$ & $(0.585)$ & $(0.013)$ \\
\hline
\end{tabular}

Note. Estimations conducted using two alternative competition indexes in the two cases where only years 1999 and 2011 are considered, and where all the years over the 1999-2011 period are considered. LOCI Index: LOgit Competition Index; Instrumented C Index: one minus instrumented HHI where instrumented HHI was constructed using Kessler and McClellan (2000)'s procedure. Only the estimated competition effects of the reform are reported. All specifications include as control variables individual characteristics related to case-mix (interactions between sex and age brackets, detailed information on secondary diagnoses and comorbidities, average income in the municipality) and procedure (treatment with angioplasty). For specifications estimated on years 1999 and 2011 only, control variables also include a dummy for year 2011, its interaction with a dummy for private status, the competition index and its interaction with a dummy for private status. For specifications estimated on the whole 1999-2011 period, control variables also include dummies for interactions between time periods and hospital statuses, the competition index, its interactions with the time trend and the dummy for private status. 
Figure 1. Description of hospital ownership statuses in France

\begin{tabular}{|c|c|c|c|c|c|}
\hline Type & $\begin{array}{l}\text { University } \\
\text { hospital }\end{array}$ & $\begin{array}{l}\text { Non- } \\
\text { teaching } \\
\text { public } \\
\text { hospitals }\end{array}$ & Non-profit hospitals & \multicolumn{2}{|c|}{ For-profit hospitals } \\
\hline Public status & \multicolumn{2}{|c|}{ Yes } & \multicolumn{3}{|c|}{ No } \\
\hline Public sector & \multicolumn{3}{|c|}{ Yes } & \multicolumn{2}{|l|}{ No } \\
\hline Ownership & \multicolumn{2}{|c|}{ State-Owned } & Non-Profit & \multicolumn{2}{|c|}{ For-Profit } \\
\hline $\begin{array}{l}\text { Workers' status for non- } \\
\text { doctors }\end{array}$ & \multicolumn{2}{|c|}{$\begin{array}{c}\text { Civil servants and salaried } \\
\text { workers }\end{array}$} & \multicolumn{3}{|c|}{ Salaried workers } \\
\hline Workers' status for doctors & \multicolumn{2}{|c|}{ Civil servants } & \multicolumn{3}{|c|}{ Salaried workers and private practice } \\
\hline Profit & \multicolumn{2}{|c|}{$\begin{array}{l}\text { No profit } \\
\text { Surplus given to the state }\end{array}$} & $\begin{array}{l}\text { Cannot make profit but } \\
\text { surplus can be re- } \\
\text { invested }\end{array}$ & \multicolumn{2}{|c|}{ Can make profit } \\
\hline \multicolumn{6}{|l|}{ Before reform } \\
\hline Funding & \multicolumn{3}{|c|}{ Global budget } & Fee-for-service & Per diem \\
\hline Medical devices & \multicolumn{3}{|c|}{ No additional budget } & \multicolumn{2}{|c|}{$\begin{array}{l}\text { Reimbursed per unit, } \\
\text { tariff defined at the } \\
\text { local level }\end{array}$} \\
\hline Research activities & $\begin{array}{l}\text { Additional } \\
\text { budget }^{18}\end{array}$ & No & No & No & \\
\hline \multicolumn{6}{|l|}{ After reform } \\
\hline Funding & \multicolumn{5}{|c|}{ DRG-based payment } \\
\hline Medical devices & \multicolumn{5}{|c|}{$\begin{array}{l}\text { - When on a restricted list, reimbursed per unit, tariff determined at the national } \\
\text { level } \\
\text { - When not on the list, no additional payment }\end{array}$} \\
\hline Research activities & $\begin{array}{l}\text { Additional } \\
\text { budget }^{22}\end{array}$ & No & No & No & \\
\hline
\end{tabular}

\footnotetext{
${ }_{18}$ Part of the additional budget for research activities may have been used for medical devices such as stents for AMI patients.
} 
Figure 2. average yearly competition index and length of stay over the 1999-2011 period

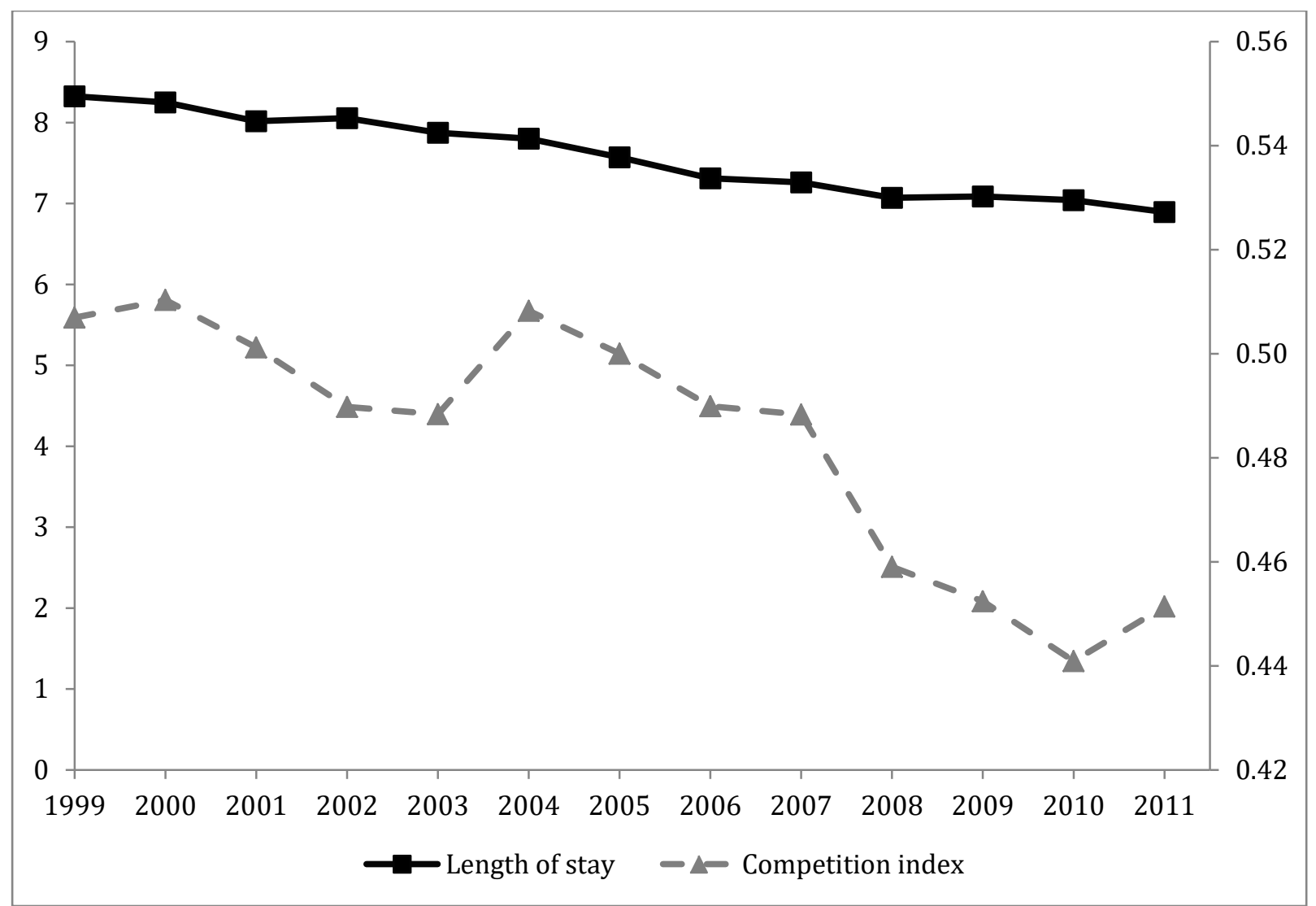

Note. The x-axis gives the year. The y-axis for the length of stay is on the left-hand side, and that for the competition index is on the right-hand side. 
Figure 3. Yearly mortality rate within 30 days by hospital status over the 1999-2011 period

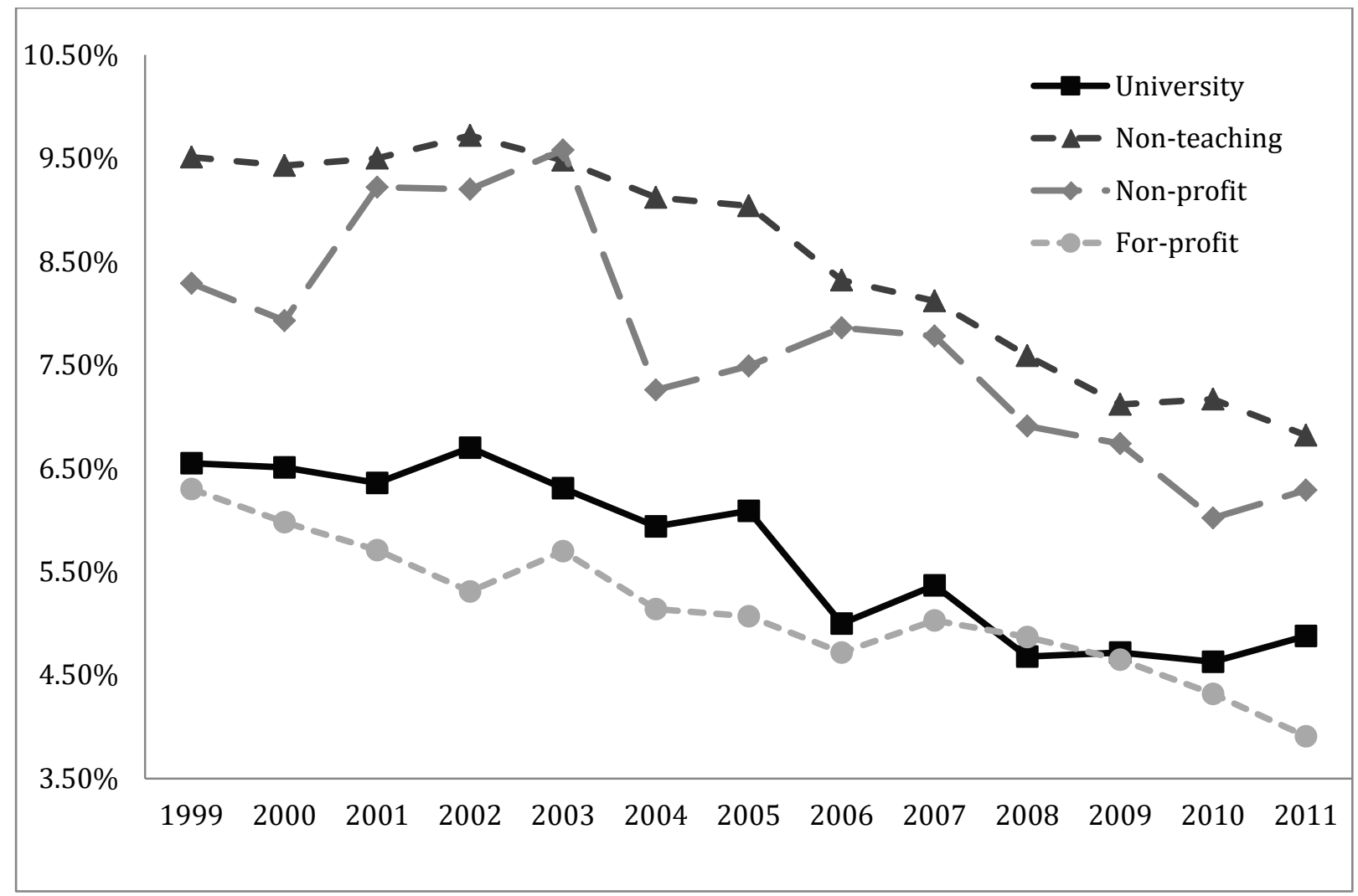

Note. The $\mathrm{x}$-axis gives the year and the $\mathrm{y}$-axis gives the mortality rate within 30 days for a given hospital status. Transfers and home returns of patients within 30 days are taken into account in the denominator of the yearly mortality rate but they are counted as zero at the numerator in line with the literature. 
Figure 4. Plot of hospital mortality rate against competition index within $30 \mathrm{~km}$

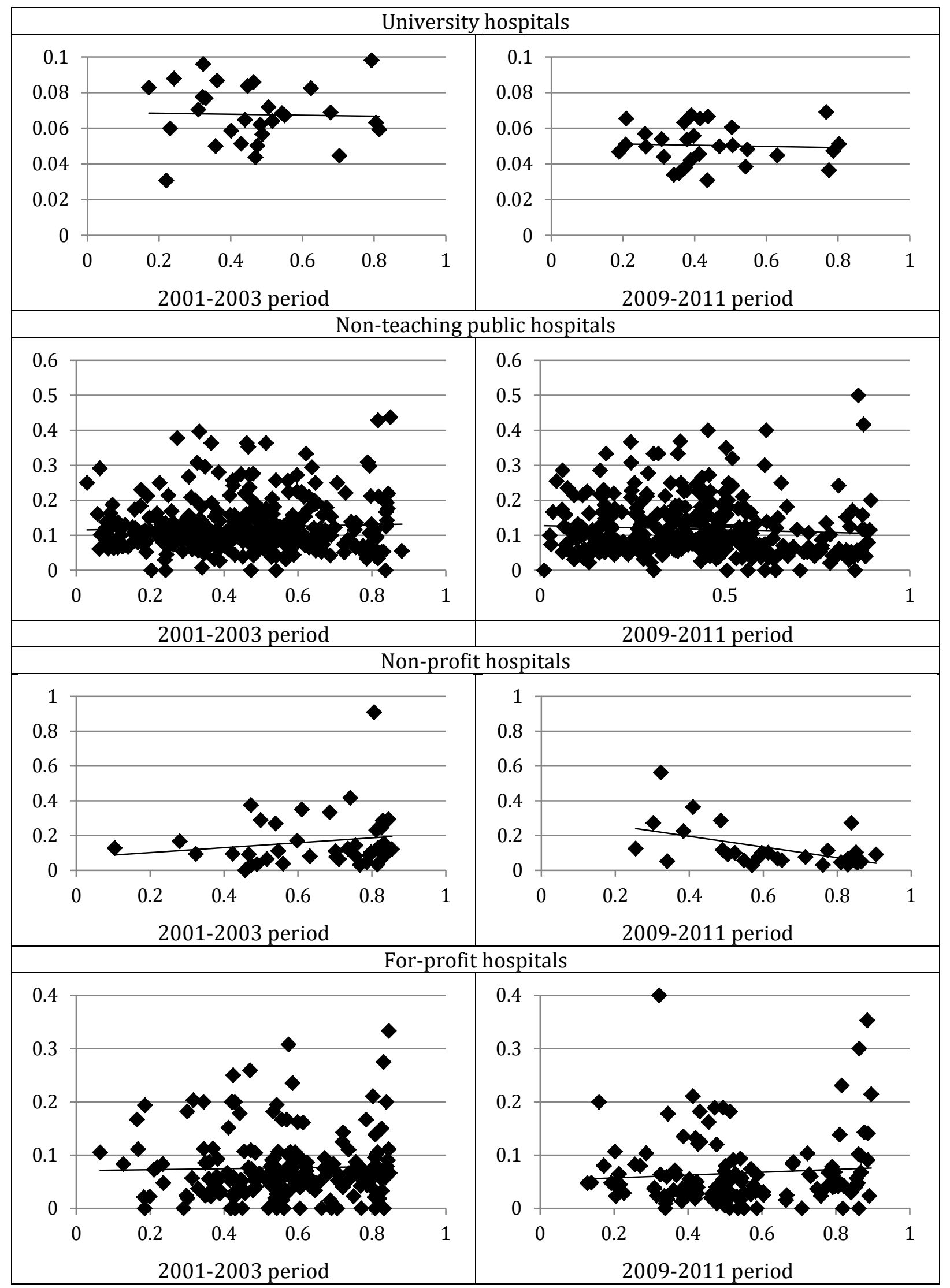


Note. The $\mathrm{x}$-axis gives the value of the competition index and the $\mathrm{y}$-axis gives the hospital mortality rate within 30 days. Each dot corresponds to a hospital. We restrict the sample to hospitals admitting at least 10 patients during the period which is considered (2001-2003 or 2009-2011) to retain only hospitals for which the mortality rate is computed with enough precision. 


\section{Appendix A. Details on the Logit Concentration index}

We explain in more details here how the Logit Concentration Index (LOCI) is constructed following Akosa, Gaynor and Vogt (2006) and Bynum, Colla and Skinner (2016). The LOCI index for a given hospital captures the fractions of patients in municipalities which are not admitted in that hospital. It therefore corresponds to the potential market of the hospital. The LOCI is given by the formula:

$$
\Lambda_{j}=\sum_{m \in \Phi_{j}} \frac{N_{m} S_{m \rightarrow j}}{\sum_{m \in \Phi_{j}} N_{m} S_{m \rightarrow j}}\left(1-S_{m \rightarrow j}\right)
$$

where $m$ indexes the municipality, $\Phi_{j}$ is the set of municipalities from which the hospital draws patients, $S_{m \rightarrow j}$ is the share of patients in municipality $m$ admitted in hospital $j$ and $N_{m}$ is the number of patients in municipality $m$.

The LOCI takes the value zero when the hospital has admitted every patient living in municipalities from which it draws patients. The LOCI tends to one when the market is perfectly competitive and $S_{m \rightarrow j}$ tends to zero for all municipalities. It is important to note that the HHI and LOCI differ in their treatment of large and small hospitals. Consider a geographic area consisting in two municipalities such that there is a large hospital in a municipality and a small one in the other municipality. Suppose that each hospital draws the same proportional number of patients from each municipality. The HHI is identical for the two municipalities and so is then the HHI of the two hospitals, as a hospital HHI is computed as the weighted average of municipality HHIs (where the weight is the hospital share of patients coming from the municipality). By contrast, the LOCI is higher for the small hospital because the fraction of patients in each municipality not admitted in that hospital is larger. This index better captures the idea that there would be a larger potential market for the small hospital and thus more incentives for competition. 


\section{Appendix B. Quantification of the competition effect of the policy}

We propose a counterfactual exercise to quantify more precisely the competition effect of the reform on mortality for patients in hospitals of a given status or for the whole population of patients. For that purpose, we consider one of the specifications we estimated to evaluate this competition effect and we restrict the sample to years after the implementation of the reform. When considering specification (2), this amounts to keeping year 2011 only, whereas when considering specification (3), this amounts to keeping all the years within the 2008-2011 period.

We compute for each patient the probability of death within a given duration of stay derived from the model when the competition effect of the reform is taken into account. This is consistent with the observed situation in which the reform has been implemented. We also compute the same probability, but when the competition effect of the reform is fixed to zero. This is consistent with the counterfactual situation in which the reform has no competition effect. We then average the probabilities of mortality within a given duration of stay for the subpopulation of patients in hospitals of a given status respectively in the observed and counterfactual situations. The difference in these average probabilities is a measure of the competition effect of the reform on mortality.

More formally, denote by $M_{i, t}(\ell)$ a dummy taking the value one if individual $i$ admitted in year $t$ dies within the first $\ell$ days after hospital admission (and zero otherwise). For hospitals of a given status $q$, the competition effect of the reform in the long run is computed as:

$$
\begin{gathered}
\Delta_{q}=E\left[P\left(M_{i, t}(\ell)=1 \mid X_{i, t}\right) \mid i \in q, t=2011\right] \\
-E\left[P\left(M_{i, t}(\ell)=1 \mid X_{i}, \beta_{5}=0, \beta_{6}=0\right) \mid i \in q, t=2011\right]
\end{gathered}
$$

where $i \in q$ denotes the fact that patient $i$ was admitted in a hospital of status $q$. It is possible to derive formulas for the probabilities of mortality within $\ell$ days from the model. Indeed, we have:

$$
P\left(M_{i, t}(\ell)=1 \mid X_{i, t}\right)=1-\exp \left[-\mu\left(X_{i, t}\right) \Lambda_{h(i)}(\ell)\right]
$$

where the hospital admitting the patient $h(i)$ is of status $q, \Lambda_{h}(\ell)=\int_{0}^{\ell} \lambda_{h}(\ell) d \ell$ is the integrated hazard for hospital $h$ and $\mu\left(X_{i, t}\right)$ is the effect of explanatory variables given by equation (2). Denote by $\mu^{c}\left(X_{i, t}\right)$ the counterfactual of $\mu\left(X_{i, t}\right)$ in which the coefficients $\beta_{5}$ and $\beta_{6}$ have been fixed to zero. We have: 


$$
P\left(M_{i, t}(\ell)=1 \mid X_{i, t}, \beta_{5}=0, \beta_{6}=0\right)=1-\exp \left[-\mu^{c}\left(X_{i, t}\right) \Lambda_{h(i)}(\ell)\right]
$$

The probabilities of mortality given by (5) and (6) can be computed by replacing each integrated hazard at day $\ell, \Lambda_{h}(\ell)$, with its Breslow's estimator, $\mu\left(X_{i, t}\right)$ with the estimator obtained when replacing the coefficients $\beta_{i}, i=1, \ldots, 7$ with their estimators, and $\mu^{c}\left(X_{i, t}\right)$ with the estimator obtained when replacing the coefficients $\beta_{1}, \beta_{2}, \beta_{3}, \beta_{4}$ and $\beta_{7}$ with their estimators. The expected probabilities of mortality involved in (4) can finally be computed as the difference in the averages of estimated probabilities of mortality over the subpopulation of patients in hospitals of a given status. We can then recover the competition effect of the reform for the overall population of patients as the weighted average of competition effects obtained for every hospital status:

$$
\Delta=\frac{1}{N} \sum_{q} N_{q} \Delta_{q}
$$

where $N_{q}$ is the number of patients in hospitals of status $q$ and $N$ is the total number of patients. This competition effect takes into account the fact that the competition index can have an effect which is specific to the hospital status.

The competition effect of the reform over the 2008-2011 period can be computed in the same way based on equation (3). For a hospital of given status $h$, this effect is given by:

$$
\begin{gathered}
\Delta_{q}=E\left[P\left(M_{i, t}(\ell)=1 \mid X_{i, t}\right) \mid i \in q, 2008 \leq t \leq 2011\right] \\
-E\left[P\left(M_{i, t}(\ell)=1 \mid X_{i, t}, \gamma_{9}=0, \gamma_{10}=0, \gamma_{11}=0\right) \mid i \in q, 2008 \leq t \leq 2011\right]
\end{gathered}
$$

As before, the competition effect for the overall population can be recovered using formula (7). 


\section{Appendix C. Additional Results}

Table C.1. Stratified Cox Model estimations, estimated coefficients for patient variables

\begin{tabular}{|c|c|c|}
\hline Variables & Between 1999 and 2011 & Whole 1999-2011 period \\
\hline \multirow[t]{2}{*}{ Female, 55-65 } & $0.365^{*}$ & $0.391 * * *$ \\
\hline & $(0.194)$ & $(0.078)$ \\
\hline \multirow[t]{2}{*}{ Female, 65-75 } & $0.971 * * *$ & $0.901 * * *$ \\
\hline & $(0.165)$ & $(0.066)$ \\
\hline \multirow[t]{2}{*}{ Female, 75-85 } & $1.412^{* * *}$ & $1.353^{* * *}$ \\
\hline & $(0.159)$ & $(0.063)$ \\
\hline \multirow[t]{2}{*}{ Female, more than 85} & $1.893^{* * *}$ & $1.778^{* * *}$ \\
\hline & $(0.158)$ & $(0.063)$ \\
\hline \multirow[t]{2}{*}{ Male, 35-55 } & $-0.558^{* * *}$ & $-0.413^{* * *}$ \\
\hline & $(0.175)$ & $(0.069)$ \\
\hline \multirow[t]{2}{*}{ Male, 55-65 } & 0.195 & $0.210^{* * *}$ \\
\hline & $(0.166)$ & $(0.066)$ \\
\hline \multirow[t]{2}{*}{ Male, 65-75 } & $0.674^{* * *}$ & $0.712^{* * *}$ \\
\hline & $(0.160)$ & $(0.064)$ \\
\hline \multirow[t]{2}{*}{ Male, 75-85 } & $1.208^{* * *}$ & $1.248^{* * *}$ \\
\hline & $(0.159)$ & $(0.063)$ \\
\hline \multirow[t]{2}{*}{ Male, more than 85} & $1.749 * * *$ & $1.696^{* * *}$ \\
\hline & $(0.160)$ & $(0.063)$ \\
\hline \multirow[t]{2}{*}{ Alcohol problem } & 0.091 & $0.322^{* * *}$ \\
\hline & $(0.133)$ & $(0.043)$ \\
\hline \multirow[t]{2}{*}{ Smoking problem } & $-0.451 * * *$ & $-0.487 * * *$ \\
\hline & $(0.072)$ & $(0.029)$ \\
\hline \multirow[t]{2}{*}{ Obesity problem } & $-0.458^{* * *}$ & $-0.323 * * *$ \\
\hline & $(0.074)$ & $(0.027)$ \\
\hline \multirow[t]{2}{*}{ Diabetes } & $-0.122^{* * *}$ & $-0.084 * * *$ \\
\hline & $(0.032)$ & $(0.012)$ \\
\hline \multirow[t]{2}{*}{ Hypertension } & $-0.634 * * *$ & $-0.599 * * *$ \\
\hline & $(0.030)$ & $(0.011)$ \\
\hline \multirow[t]{2}{*}{ Renal failure } & $0.398^{* * *}$ & $0.333^{* * *}$ \\
\hline & $(0.031)$ & $(0.011)$ \\
\hline \multirow[t]{2}{*}{ Valvular disease } & $-0.335^{* * *}$ & $-0.345^{* * *}$ \\
\hline & $(0.047)$ & $(0.017)$ \\
\hline \multirow[t]{2}{*}{ Peripheral arterial disease } & -0.017 & $-0.033^{* *}$ \\
\hline & $(0.044)$ & $(0.017)$ \\
\hline \multirow[t]{2}{*}{ Other vascular disease } & $0.275^{* * *}$ & $0.264 * * *$ \\
\hline & $(0.048)$ & $(0.016)$ \\
\hline
\end{tabular}


Other ischemic disease

$-0.199 * * *$

(0.053)

$0.114^{* * *}$

$(0.027)$

$0.682^{* * *}$

(0.016)

-0.601 ***

(0.038)

$-2.72 \mathrm{e}-05$

(2.43e-05)
$-0.192 * * *$

(0.020)

$0.077 * * *$

(0.020)

$0.617 * * *$

(0.006)

$-0.855^{* * *}$

(0.015)

1.98e-05

(4.62e-05)

Note. ${ }^{*}$ significant at $10 \%$ level; $* *$ significant at $5 \%$ level; $* * *$ significant at $1 \%$ level. Standard errors are reported in parentheses. Other estimated coefficients for the specification estimated from years 1999 and 2011 only are reported in Table 2, column (1), and those for the specification estimated over the whole 1999-2011 period are reported in Table 3, column (1). 
Table C.2. Competition effect of the reform on mortality between 1999 and 2011, estimations for alternative specifications

\begin{tabular}{|c|c|c|c|c|c|c|}
\hline \multirow[t]{2}{*}{ Variable } & \multirow[t]{2}{*}{ All hospitals } & \multirow{2}{*}{$\begin{array}{l}\text { For-profit } \\
\text { hospitals }\end{array}$} & \multicolumn{4}{|c|}{ Hospitals in the public sector } \\
\hline & & & All & Non-profit & University & $\begin{array}{l}\text { Non- } \\
\text { teaching }\end{array}$ \\
\hline \multicolumn{7}{|l|}{ Ordinary Least Squares } \\
\hline $\mathrm{C} *$ Private sector & -0.0100 & -0.0095 & & & & \\
\hline * Year 2011 & $(0.0077)$ & $(0.0076)$ & & & & \\
\hline $\mathrm{C} *$ Public sector & 0.0031 & & 0.0029 & $-0.1040 *$ & 0.0135 & -0.0040 \\
\hline * Year 2011 & $(0.0033)$ & & $(0.0033)$ & $(0.0459)$ & $(0.0099)$ & $(0.0041)$ \\
\hline \multicolumn{7}{|l|}{$\begin{array}{l}\text { Within Model, Least } \\
\text { Squares }\end{array}$} \\
\hline $\mathrm{C} *$ Private sector & -0.0067 & 0.0064 & & & & \\
\hline * Year 2011 & $(0.0085)$ & $(0.0083)$ & & & & \\
\hline $\mathrm{C} *$ Public sector & 0.0048 & & 0.0047 & $-0.1010^{*}$ & 0.0084 & -0.0038 \\
\hline * Year 2011 & $(0.0035)$ & & $(0.0035)$ & $(0.0519)$ & $(0.0242)$ & $(0.0045)$ \\
\hline \multicolumn{7}{|l|}{ Cox Model } \\
\hline $\mathrm{C} *$ Private sector & -0.153 & -0.238 & & & & \\
\hline * Year 2011 & $(0.299)$ & $(0.291)$ & & & & \\
\hline$C *$ Public sector & -0.072 & & -0.079 & $-1.761 * *$ & $0.429 * *$ & $-0.207^{*}$ \\
\hline * Year 2011 & $(0.099)$ & & $(0.099)$ & $(0.693)$ & $(0.193)$ & $(0.122)$ \\
\hline \multicolumn{7}{|l|}{$\begin{array}{l}\text { Cox-Fixed effect } \\
\text { Model }\end{array}$} \\
\hline$C *$ Private sector & -0.406 & -0.489 & & & & \\
\hline * Year 2011 & $(0.346)$ & $(0.369)$ & & & & \\
\hline$C *$ Public sector & -0.053 & & -0.035 & $-1.470^{*}$ & 0.205 & -0.035 \\
\hline * Year 2011 & $(0.110)$ & & $(0.110)$ & $(0.863)$ & $(0.317)$ & $(0.137)$ \\
\hline \multicolumn{7}{|l|}{ Stratified Cox Model } \\
\hline$C *$ Private sector & -0.384 & -0.305 & & & & \\
\hline * Year 2011 & $(0.360)$ & $(0.354)$ & & & & \\
\hline$C *$ Public sector & -0.034 & & -0.004 & $-1.446^{*}$ & 0.164 & -0.021 \\
\hline * Year 2011 & $(0.111)$ & & $(0.111)$ & $(0.878)$ & $(0.103)$ & $(0.139)$ \\
\hline Patient characteristics & Yes & Yes & Yes & Yes & Yes & Yes \\
\hline $\mathrm{N}$ & 102,034 & 20,099 & 80,453 & 3,235 & 30,591 & 46,420 \\
\hline \multicolumn{7}{|c|}{$\begin{array}{l}\text { Note. } * \text { significant at } 10 \% \text { level; } * * \text { significant at } 5 \% \text { level; } * * * \text { significant at } 1 \% \text { level. Standard errors are reported in } \\
\text { parentheses. For the Ordinary Least Squares and the Within estimations, the dependent variable is a dummy taking } \\
\text { the value one if the patient died at the hospital within } 30 \text { days after her admission following an AMI. C=1-HH } \\
\text { where HHI is the hospital weighted average of Herfindahl-Hirschman indexes computed for every patient taking } \\
\text { into account establishments within a } 30 \mathrm{~km} \text { radius around her place of residence. Only the estimated competition } \\
\text { effects of the reform are reported. All specifications include as control variables a dummy for year } 2011 \text {, its } \\
\text { interaction with a dummy for private status, the competition index, its interaction with a dummy for private status as } \\
\text { well as individual characteristics related to case-mix (interactions between sex and age brackets, detailed information } \\
\text { on secondary diagnoses and comorbidities, average income in the municipality) and procedure (treatment with } \\
\text { angioplasty). }\end{array}$} \\
\hline
\end{tabular}


Table C.3. Competition effect of the reform on mortality over the 1999-2011 period, estimations for alternative specifications

\begin{tabular}{|c|c|c|c|c|c|c|}
\hline \multirow[t]{2}{*}{ Variable } & \multirow[t]{2}{*}{ All hospitals } & \multirow{2}{*}{$\begin{array}{l}\text { For-profit } \\
\text { hospitals }\end{array}$} & \multicolumn{4}{|c|}{ Hospitals in the public sector } \\
\hline & & & All & Non-profit & University & $\begin{array}{l}\text { Non- } \\
\text { teaching }\end{array}$ \\
\hline \multicolumn{7}{|l|}{ Ordinary Least Squares } \\
\hline $\mathrm{C} *$ Public sector & $-0.0051^{* *}$ & & $-0.0067 * *$ & -0.0271 & 0.0009 & $-0.0099 * *$ \\
\hline$*($ Year $>=2004)$ & $(0.0024)$ & & $(0.0029)$ & $(0.0185)$ & $(0.0045)$ & $(0.0040)$ \\
\hline $\mathrm{C} *$ Public sector & $0.0038^{*}$ & & 0.0021 & $-0.0529 * * *$ & 0.0056 & 0.0028 \\
\hline$*($ Year $>=2008)$ & $(0.0023)$ & & $(0.0031)$ & $(0.0200)$ & $(0.0050)$ & $(0.0041)$ \\
\hline$C *$ Private sector & -0.0016 & -0.0057 & & & & \\
\hline$*($ Year $>=2005)$ & $(0.0011)$ & $(0.0047)$ & & & & \\
\hline \multicolumn{7}{|c|}{ Within Model, Least Squares } \\
\hline C $*$ Public sector & -0.0010 & & -0.0031 & -0.0046 & -0.0022 & -0.0395 \\
\hline$*($ Year $>=2004)$ & $(0.0021)$ & & $(0.0027)$ & $(0.0132)$ & $(0.0033)$ & $(0.0312)$ \\
\hline$C *$ Public sector & 0.0021 & & -0.0041 & $-0.0679 * *$ & 0.0034 & -0.0003 \\
\hline$*($ Year $>=2008)$ & $(0.0021)$ & & $(0.0025)$ & $(0.0336)$ & $(0.0035)$ & $(0.0028)$ \\
\hline $\mathrm{C} *$ Private sector & -0.0015 & 0.0010 & & & & \\
\hline$*($ Year $>=2005)$ & $(0.0011)$ & $(0.0027)$ & & & & \\
\hline \multicolumn{7}{|l|}{ Cox Model } \\
\hline $\mathrm{C} *$ Public sector & -0.056 & & -0.118 & -0.012 & -0.284 & $-0.209 * *$ \\
\hline$*($ Year $>=2004)$ & $(0.059)$ & & $(0.077)$ & $(0.372)$ & $(0.271)$ & $(0.085)$ \\
\hline$C *$ Public sector & 0.003 & & -0.066 & $-0.626^{*}$ & $0.541^{*}$ & -0.082 \\
\hline$*($ Year $>=2008)$ & $(0.053)$ & & $(0.077)$ & $(0.366)$ & $(0.300)$ & $(0.083)$ \\
\hline$C *$ Private sector & -0.032 & -0.012 & & & & \\
\hline$*($ Year $>=2005)$ & $(0.087)$ & $(0.021)$ & & & & \\
\hline \multicolumn{7}{|l|}{ Cox-Fixed effect Model } \\
\hline$C *$ Public sector & -0.059 & & -0.117 & -0.142 & -0.049 & -0.085 \\
\hline$*($ Year $>=2004)$ & $(0.061)$ & & $(0.080)$ & $(0.464)$ & $(0.173)$ & $(0.096)$ \\
\hline$C *$ Public sector & -0.070 & & $-0.141 *$ & $-0.874^{*}$ & 0.021 & -0.085 \\
\hline$*($ Year $>=2008)$ & $(0.055)$ & & $(0.078)$ & $(0.448)$ & $(0.177)$ & $(0.094)$ \\
\hline$C *$ Private sector & -0.040 & -0.057 & & & & \\
\hline$*($ Year $>=2005)$ & $(0.090)$ & $(0.092)$ & & & & \\
\hline \multicolumn{7}{|l|}{ Stratified Cox Model } \\
\hline$C *$ Public sector & -0.077 & & -0.121 & -0.133 & -0.038 & $-0.184 * *$ \\
\hline$*($ Year $>=2004)$ & $(0.061)$ & & $(0.081)$ & $(0.469)$ & $(0.174)$ & $(0.088)$ \\
\hline$C *$ Public sector & -0.077 & & $-0.143^{*}$ & $-0.964^{* *}$ & 0.018 & -0.033 \\
\hline$*($ Year $>=2008)$ & $(0.055)$ & & $(0.080)$ & $(0.451)$ & $(0.177)$ & $(0.086)$ \\
\hline $\mathrm{C} *$ Private sector & -0.060 & -0.030 & & & & \\
\hline$*($ Year $>=2005)$ & $(0.091)$ & $(0.098)$ & & & & \\
\hline Patient characteristics & Yes & Yes & Yes & Yes & Yes & Yes \\
\hline
\end{tabular}




\begin{tabular}{lllllll}
\hline $\mathrm{N}$ & 651,453 & 135,023 & 516,430 & 20,825 & 184,835 & 310,77 \\
\hline \hline
\end{tabular}

Note. *significant at $10 \%$ level; ** significant at $5 \%$ level; *** significant at $1 \%$ level. Standard errors are reported in parentheses. For the Ordinary Least Squares and the Within estimations, the dependent variable is a dummy taking the value one if the patient died at the hospital within 30 days after her admission following an AMI. C=1-HHI where $\mathrm{HHI}$ is the hospital weighted average of Herfindahl-Hirschman indexes computed for every patient taking into account establishments within a $30 \mathrm{~km}$ radius around her place of residence. Only the estimated competition effects of the reform are reported. All specifications include as control variables dummies for interactions between time periods and hospital statuses, the competition index, its interactions with the time trend and the dummy for private status as well as individual characteristics related to case-mix (interactions between sex and age brackets, detailed information on secondary diagnoses and comorbidities, average income in the municipality) and procedure (treatment with angioplasty). 